\title{
استخدام نظم المعلومات الجغرافية في تقييم مستويات الضوضاء المرورية في مدينة

$$
\text { غزة - فلسطين }
$$

\section{علاء الدين داود الجماصي'، و غسان البرش'}

' قسم الهندسة المدنية، كلية الهنسسة و كلية العلوم، الجامعة الإسلامية، غنة - فلسطين

المستخلص. إن ظاهرة التلوث البيئي من أهم المشكلات التي تهدد عالمنا نظرًا لعلاقته المباشرة بالنثاط البشري. ومن أهم هذه

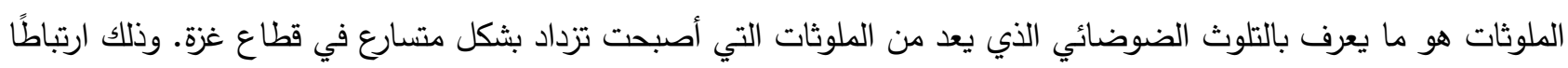

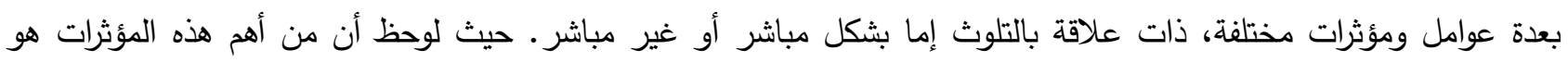

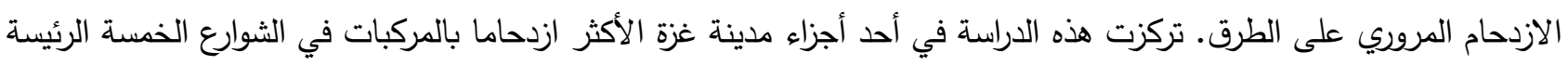

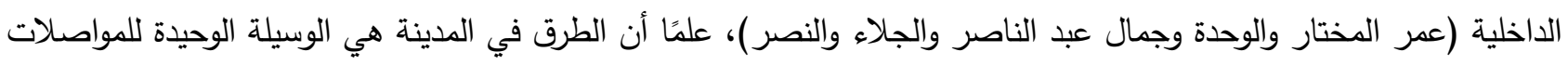

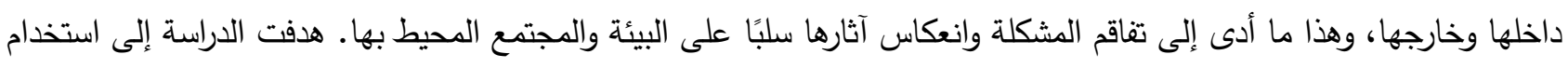

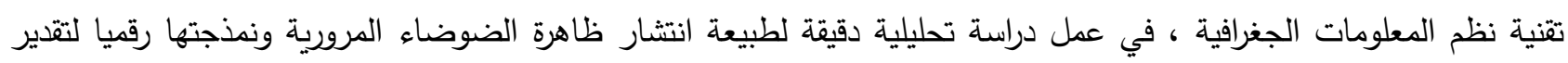

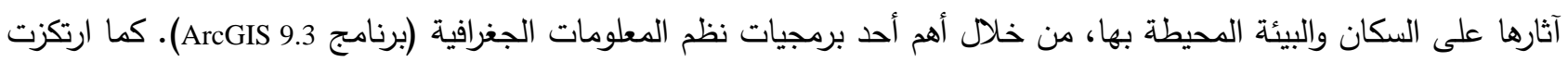

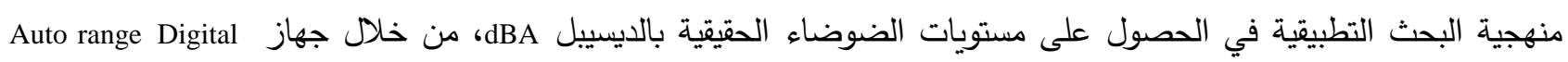
بulti meter

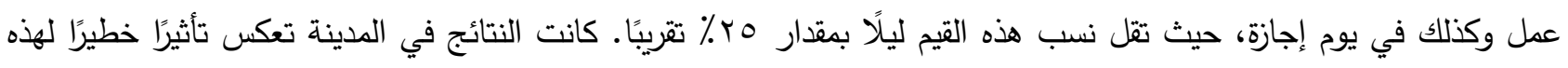

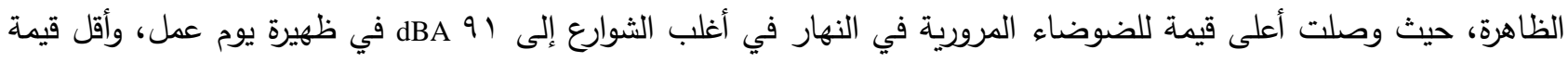

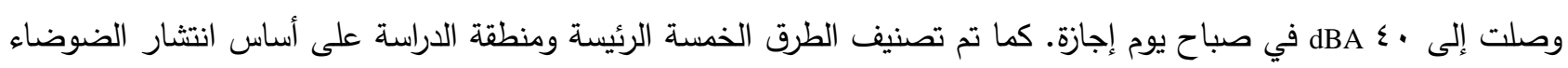

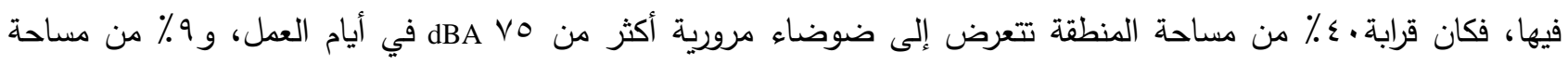

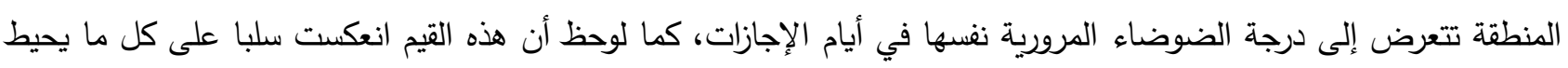

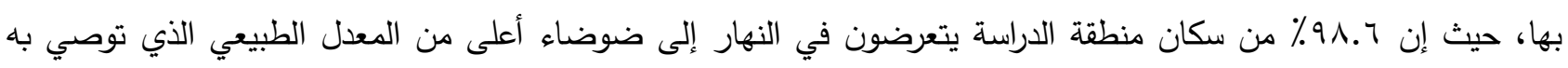

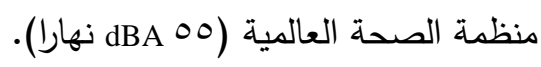
كلمات مفتاحية: نظم المعلومات الجغرافية، ندذجة تلوث الضوضاء، الضوضاء المرورية، مدينة غزة، فلسطين. 
مرات ممن يعملون في الأجواء الهادئة, وأمراض

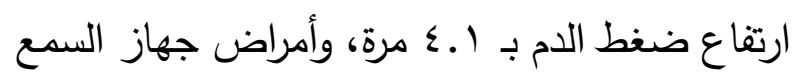

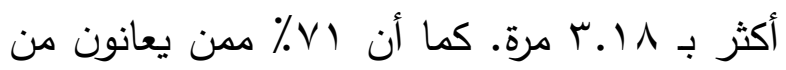
الضوضاء يعانون أيضًا من آلالامًا في الرأس

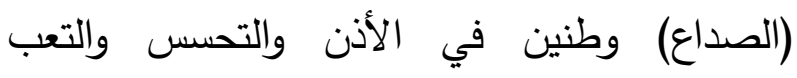

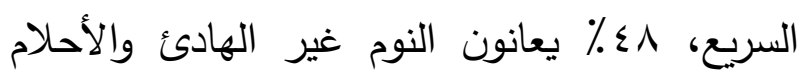

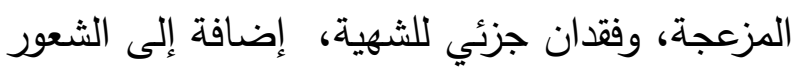
بالضيق والانقباض، وهذا ينعكس في القدرة على لى الفي

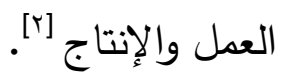

هذا البحث تم تطبيقه في مدينة غزة، الواقعة

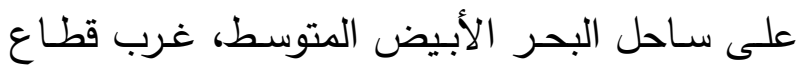
غزة جنوب فلسطين، وتعد مدينة غزة هي أكبر مدن الابط

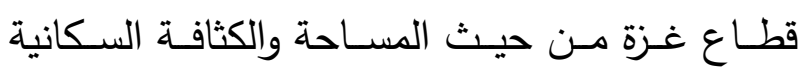
وتواجد معظم المؤسسات الحكومية، وغير الحكومية والجامعات بصفتها مركزا لقطاع غزة، وبالتالي زيادة نشاطات الإنسان والحركة الكثيفة والدائمة للمركبات على اختلاف أنواعها وأحجامها، والمعدات والآلات والورش الصناعية]ْ. إضافة إلى المولدات الكهربائية المختلفة، حيث تشكل أزمة الكهرباء مشكلة ومعاناة

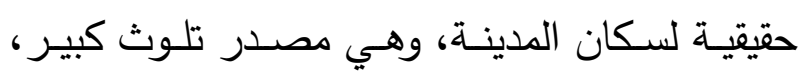

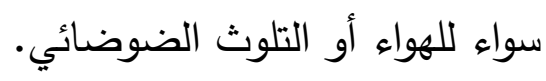

هذه الدراسة سلطت الضوء على تحديد وتقدير معدلات التلوث الضوضـائي المـروري في المدينـة، خصوصا في الشوارع الرئيسة وأماكن التجمعات مثل تقاطعات الطرق والأماكن العامة وغيرها.

\section{- 1 - المقدمة}

تعد ظاهرة التلوث البيئي من أهم المشكلات الخطرة

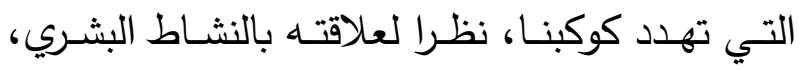
وانتشـار الملوثـات، التـي قد تلحق الضـرر بالبيئة الطبيعية [1]. ومن هذه الملوثات التي تهدد الإنسان

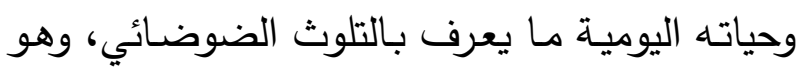

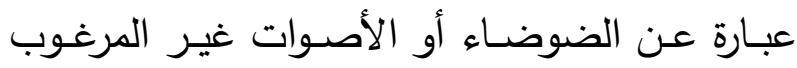

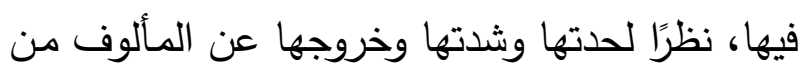
الأصوات الطبيعية، وتقاس شدته بوحدة تسمى dBA (dBA) كمـا يـرتبط التلوث الضوضـائي ارتباطًا وثيقا بالتقـدم الحضـري المواكـب لحيــاة البشـرية، وأكثـر

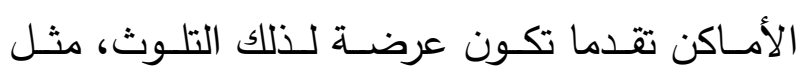
الأماكن الصناعية بسبب التوسع في استخدام الآلات

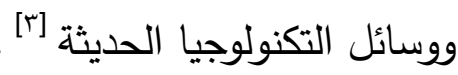
ويعد التلوث الضوضائي من الملوثات البيئية التي لها تأثير سلبي على الإنسان بشكل خاص،

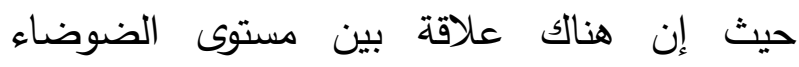

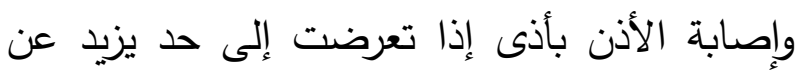

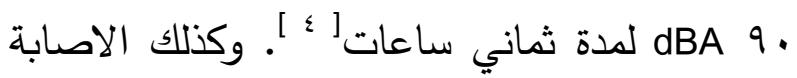

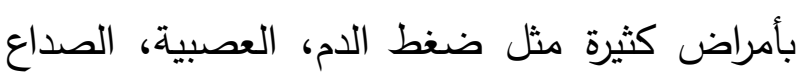
والأرق. بالإضافة الى أنها تتسبب يضرر فسيولوجي

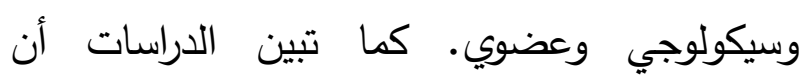
الأشخاص الذين يعانون من الضوضاء وضئ وخاصة العمال، لديهم أمراض الجملة العصبية أكثر بثلاث 
مرتفعـة، وتـأخير لمـدة طويلـة، وخاصــة في أوقـات الذروة ، وهذا نـاجم عن وجود خلل في توزيع أماكن الأنشطة التجاريـة والاجتماعيـة، بالإضـافة إلى وجود خلل في إدارة الطرق والحركة المروريـة، وذلك نتيجة عدم تطبيق خطـة مواصـلات ومرور متكاملة تشمل جميــع المنـاطق بالإضــافة للافتقــار إلـى الأدوات المساعدة في تنظيم المرور من أجهزة ومعدات وإشارات ضوئية وعلامات مرورية ثابتة.

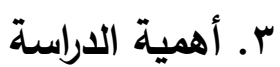

يعد التلوث الضوضـائي من الملوثات البيئية التي لهـا تـأثير سـلبي في صـحة الإنسـان بشـكل خاص، ولا شك أن التلوث الضوضـائي المروري هو أحد أهم الأنواع مواجهة للإنسـان في الحياة العملية للمجتمع بجميع فئاته العمريـة، خاصـة وأن هذا النوع مـن الضوضــاء يحتـل المصـدر الأول عالميًا في في

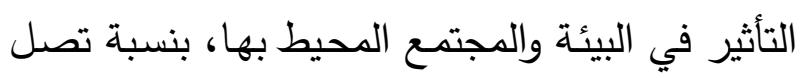

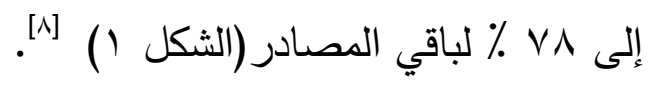

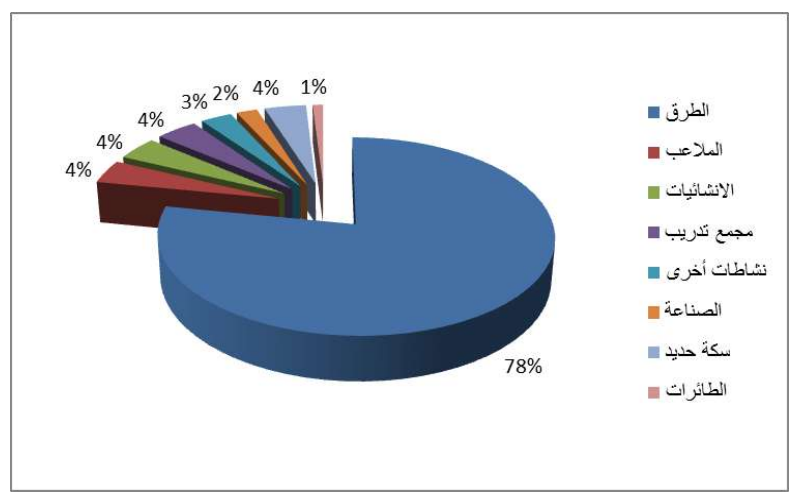

شكل 1. تصنيف مصادر الضوضاء حسب نسبة انتشارها [^].
وتــأتي أهميـــة تطبيقـــات نظــــم المعلومــات الجغرافيــة فـي تحديــد مشــكلة مصـــادر التـــوث الضوضائي المروري، لكونها وسيلة فعالة وحديثة في التعامل مـع الكم الهائل مـن البيانـات؛ حيـث تتميـز

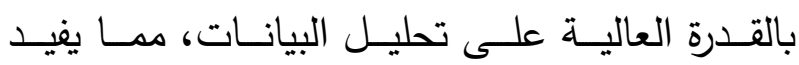
المخططين في التوصـل إلى قرارات صـحيحة، قد يصعب الوصول إليها بالطرق التقليدية]]. وذلك لما تتصف بـه من خاصية تكامل المعلومات من خلال

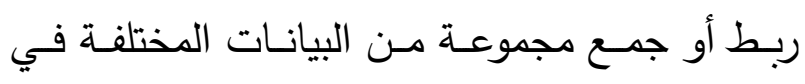
طبقات مختلفـة يمكن التعامل معها آليا، والاستفادة منها دون أن يخل هذا الاختزال والإيجاز والتخزين

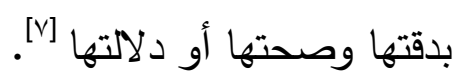

\section{Y . عرض المشكلة}

إن ظـاهرة التلوث الضوضـائي في مدينـة غزة أصـبحت تتمـو وتـزداد شـيئا فشـيئا بسـبب عوامـلـ عديدة، أهمها النمو السكاني، والتدهور الاقتصادي، بسـبب الحصـار الصـهيوني المفـروض على قطـاع غزة، وبشكل خاص الازدحام المروري بمختلف أنواع المركبات، بسبب عدم تطوير شبكات وطرق النقل المختلفــة، وعــدم الجديــة فـي تطبيــق القـــانين والتشـريعات البيئيـة المختلفـة، والإفـراط في اسـخدام المولدات الكهربائيـة في الأحيـاء السكنية والتجاريـة، بسبب الانقطاع المتزايد للتيار الكهربائي. كذلك نجد أن مدينة غزة تعاني بشكل عام من اختناقات مرويـة، وحوادث سير مختلفـة، وضوضـاء 
• المنهج التطبيقي: الذي اعتمد على إحدى

ArcGIS9.3 برمجيات نظم المعلومات الجغرافية في تمثيل المراحل التي تمر بها الدراسة.

• المنهج الوصفي: تم استخدام هذا المنهج

في التعـرف على خصـائص مدينـة غـزة المروريـة، بهدف إيجاد العلاقة بين العوامل البشرية، وطبيعة المكان الذي يتركز فيه التلوث الضوضائي المروري.

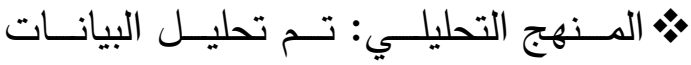

المدخلــة للتعـرف علـى حجـم المشـكلة، والأسـباب المباشـرة وغيـر المباشـرة المؤثرة في حجـم التلـوث الضوضائي المروري كما يلي:

أولًا: مرحلة جمع البيانات والمعلومات

1. تحديد أهم مصادر التلوث الضوضائي في

الشوارع الرئيسة من خلال البحث الميداني.

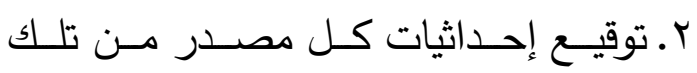

المصادر باستخدام جهاز GPS. - الموليات

r. اعتماد خريطة رقميـة لمدينـة غزة باستخدام

.ArcGIS9.3

ع. إسقاط إحداثيات مصـادر التلوث التي تم

$$
\text { تحديدها مسبقا. }
$$

هـ أخذ قراءات لمستويات التلوث الضوضـائي

Sound Level في المصادر المحدة باستخدام جهاز

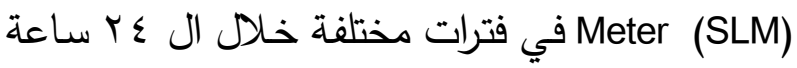

هذا ما يدعو إلى الأخذ بعين الاعتبار أهمية تطبيق هذه الدراسة في تحديد وتقدير هذا النوع من التلوث الضوضائي (المروري) للسعي في الارتقاء بالمستوى المعيشي والصحي للإنسان.

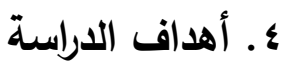

- 1 - الطهف العام

إعـداد دراسـة تحليليـة لطبيعـة انتشـار ظـاهرة الضوضاء المرورية، باستخدام تقنية نظم المعلومات الجغرافية ونمذجتها رقميا لتقدير آثارها على السكان والبيئة المحيطة بها. ـ- ألأهد/ف الخاصة

ا ـ دراسة انتشار الضوضاء المرورية نهارا في الشوارع الرئيسة في المدينة. r. دراسـة تصـنيف الطـرق الرئيسـة ومنطقــة

الدراسة حسب مستويات الضوضاء المرورية فيها. r. تقدير شـدة الضوضـاء الذي تتعرض لها واجهات المباني المحاذية للطرق الرئيسة. ع. تقدير أعداد ونسب السكان الذين يتعرضون للضوضـاء غيـر الصـحية، حسـب معـايير منظمـة

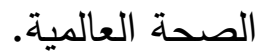

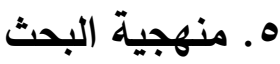

هنـاك منــاهج متعـددة تسـتخدم فـي البحـث العلمي، وكل منهج يفي بمنطلبات مرحلة معينة في الدراسة، وهذا البحث اعتمد على المنهجية التالية: 


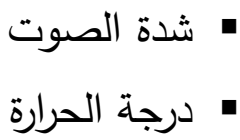

شـدة الصـوت الذي هو أحد المحددات التي

يقيسها الجهاز يعبر عن مستوى الضوضـاء ، ومن خلالـهـ يـتم قيـاس مسـتوى التــوث الضوضـائي في منطقة الدراسـة بحسب ما ورد من إجراءات لقياسات

الضوضناء، [9]

ثانيًا: مرحلة إدخال البيانات ومعالجتها

ا ـ إعداد قاعدة بيانات مكانية عن تلك المصادر .

r. تحديـد نطـاق التـأثير (Buffer) zone)

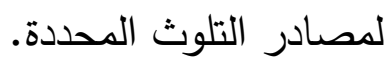

ثالثًا: مرحلة تحليل البيانات

تحليل البيانات والاستعلام من خلال البيانات

المكانية الوصفية.

رابعًا: مرحلة عرض البيانات وتحليل النتائج

ا ـ خـرائط ثنائيـة الأبعـاد 2D وثلاثيـة الأبعـاد

$.3 \mathrm{D}$

r • رسومات بيانية، وقيم إحصائية.

خامسًسا: وضـع الحسول والمقترحسات المناسـبة

\section{للمشكلة}

يوضـح الثـكل ب المنهجيـة المتبعـة في هـذا
وذلك على مدار أسبوع. حيث تم أخذ القياسات بحسب

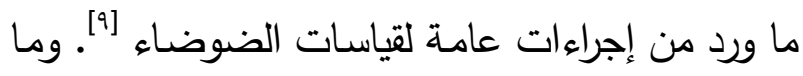
يلي تم أخذه بعين الاعتبار أثثاء القياس:

أ- مراعاة عدم وجود أيـة حاجز في محيط

القياس بحدود مترين تقريبًا.

ب- ارتقاع الجهاز أثناء عملية القياس بما لا يقل عن (Y. 1 - 1. (1) متر من سطح الأرض.

ج- يجـب أن يكـون اتجــاه اللاقـط للجهـاز

المســتخدم فـي عمليــة القيــاس باتجـــاه مصدر الضوضاء.

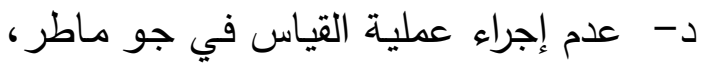
أو أيـة أحوال جويـة غير مستقرة، لما لهاء تأثير في دقة القياس. هـ - الجهـاز المسـتخدم: تـم اسـتخدام جهـاز خـاص بقيـاس الضوضـاء وهـذا الجهـاز Auto range Digital Multi meter يسمى ،Mastech MS8209 - 5 in 1 موديل وحسـب دليـل اسـتخدام ذلك الجهاز مـن الثـركة المصــنعة فهـو يقـيس خمســة محددات مختلفة هي: الجهد الكهربائي الرطوبة

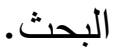




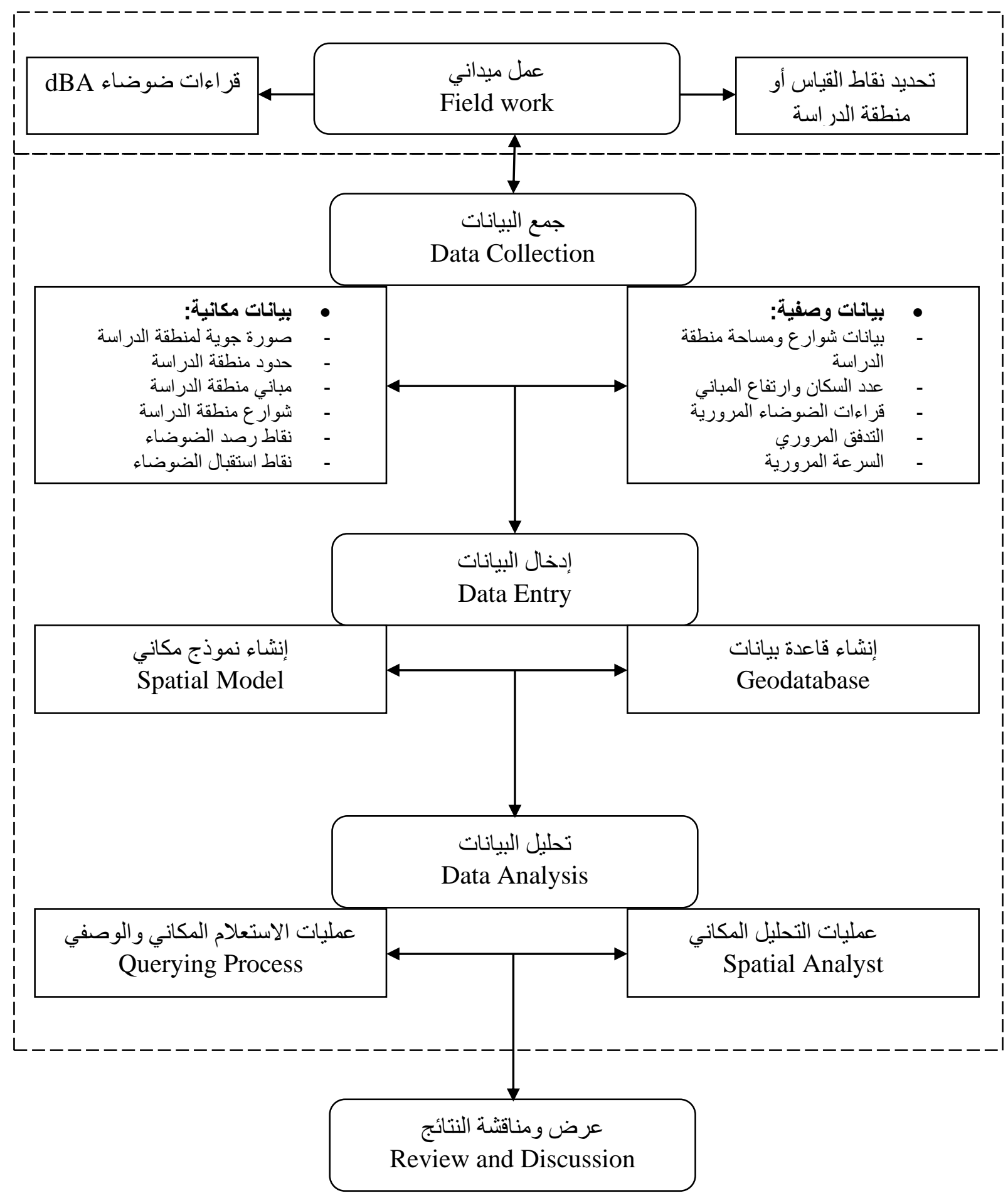

شكل r ـ المنهجية المتبعة في هذا البحث. 
مـن فترة الذروة في أيـام العمل نفسها تبعًا لمعدل التدفق المروري في هذه الفترة، الثكل ع. 7- - - ضوضـاء الطـرق فـي أريام الإجـازة وقت الذروة

يظهر مـن الثـكل ه أن قيم الضوضـاء في

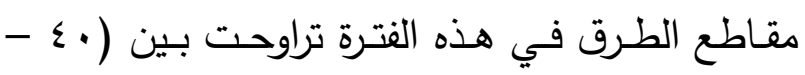

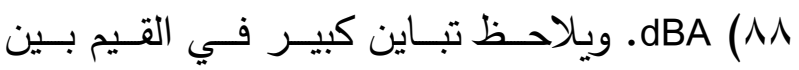
القطاعات المختلفة على منطقة الدراسة، وذلك حسب أهمية المكان من حيث الحركة المرورية. 1- - - خوضـاء الطـرق فـي أيام الإجـازة وقت

$$
\text { الصباح }
$$

فـي هــذه الفتـرة يــنففض معـدل التلـوث الضوضائي المروري بشكل كبير ، حيث تراوحت القيم

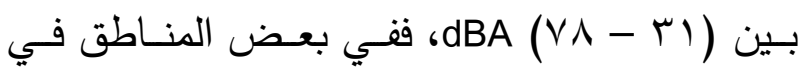
نفس الفترة انخفضت مستويات التلوث الضوضـائي

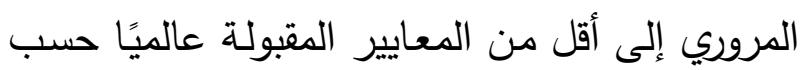
منظمة الصحة العالمية. نجد بعض المناطق خاصة في المنـاطق القربـة مـن الأسواق احتفظت بارتفاع

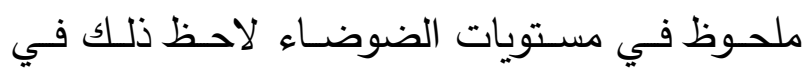

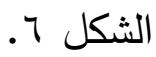
r - الضوضاء على واجهات المبانسي تتعرض الأبنيـة المتاخمـة للشـوارع الرئيسـة التي

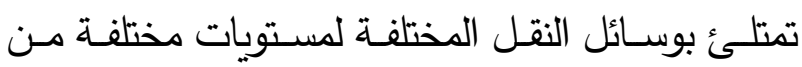
الضوضاء، تختلف حسب اكتظاظ وسائل النقل وعوامل الضوضاء الأخرى المختلفة الصادرة عن وسائل النقل.

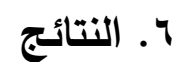

تم استعراض النتائج التي تم الحصول عليها من خـلال التحليـل المكـاني والاستعلام بواسـطة البيانـات الوصفية والمكانية باستخدام برنامج 9.3 ArcGIS. 1- 1 تصنيف ضوضاء الطرق صنفت الطرق بناءً على الضوضـاء الصـادرة

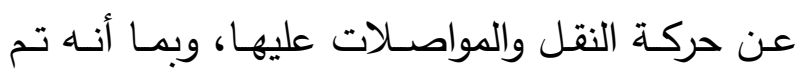
تقسيم الشوارع الخمسـة إلى قطاعات متسـاوية تقريبًا

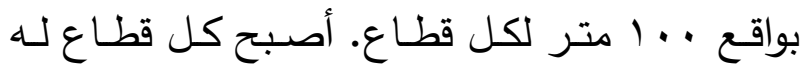
قيمة ضوضاء مختلفة عن غيره، وبناءً على القراءات

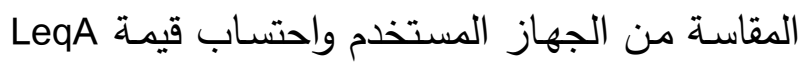

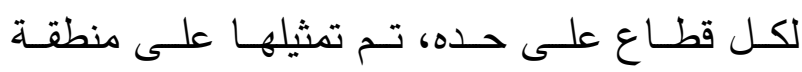

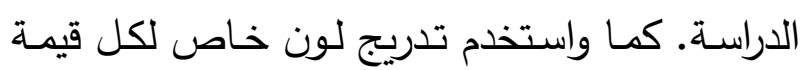

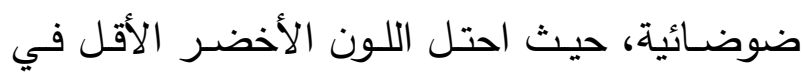

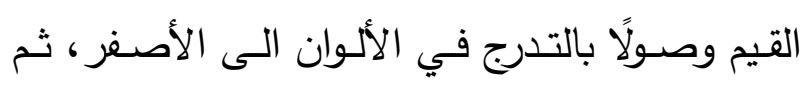
اللون الأحمر، حيث احتل أعلى القيم الضوضائية. 1- 1 - ضوضاء الطرق في ظهيتة يوم عمل

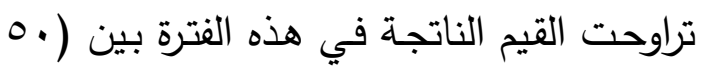
- هBA (9) -

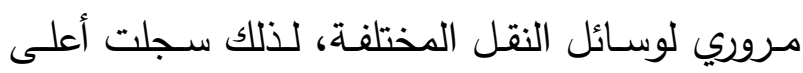
القيم في التلوث الضوضائي المروري في ظهيرة أيام

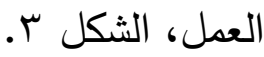
r-1 - 1 ضوضاء الطرق في صباح يوم عل تراوحت قيم الضوضـاء على الطرق في هذه

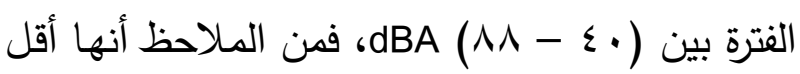




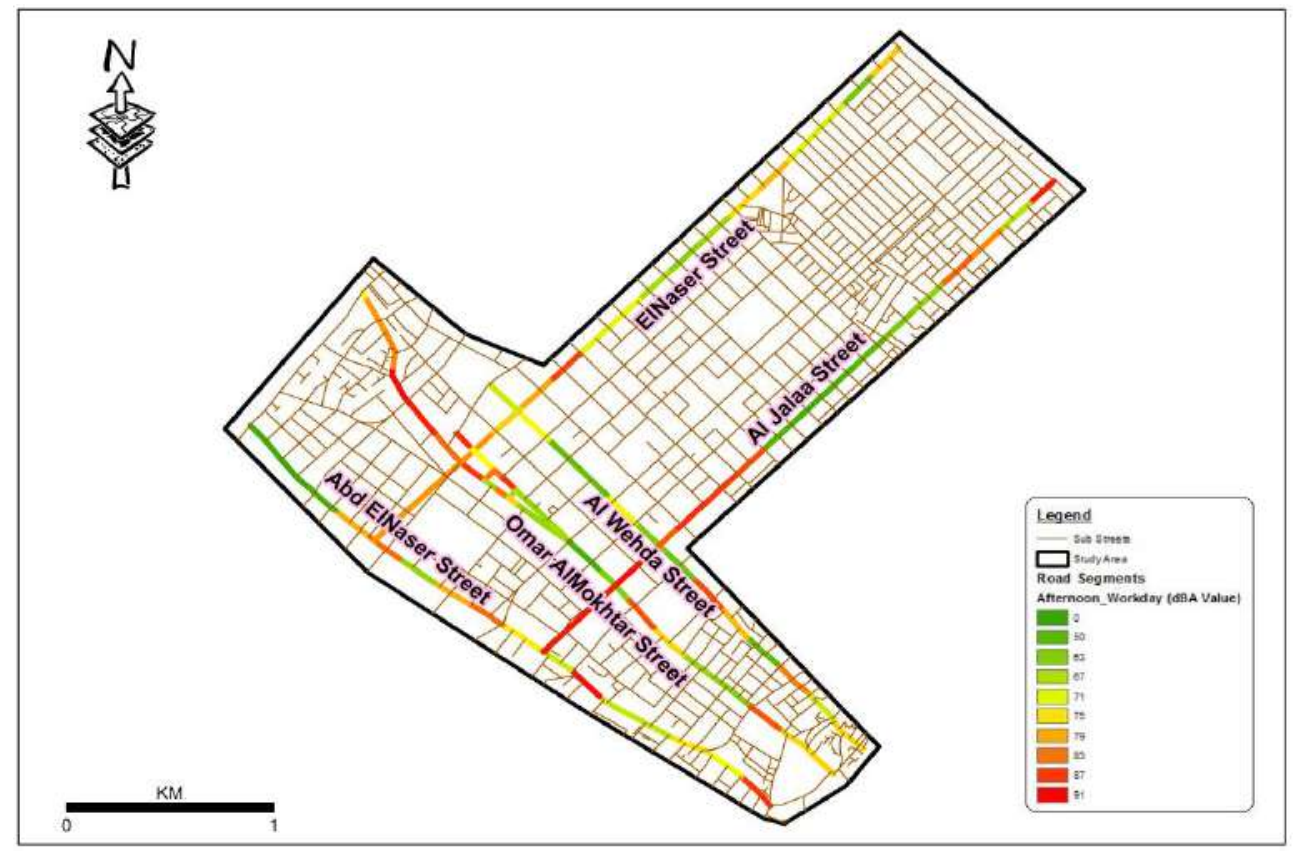

شكل r. تصنيف الشوارع على أساس معدلات الضوضاء في ظهيرة أيام العمل.

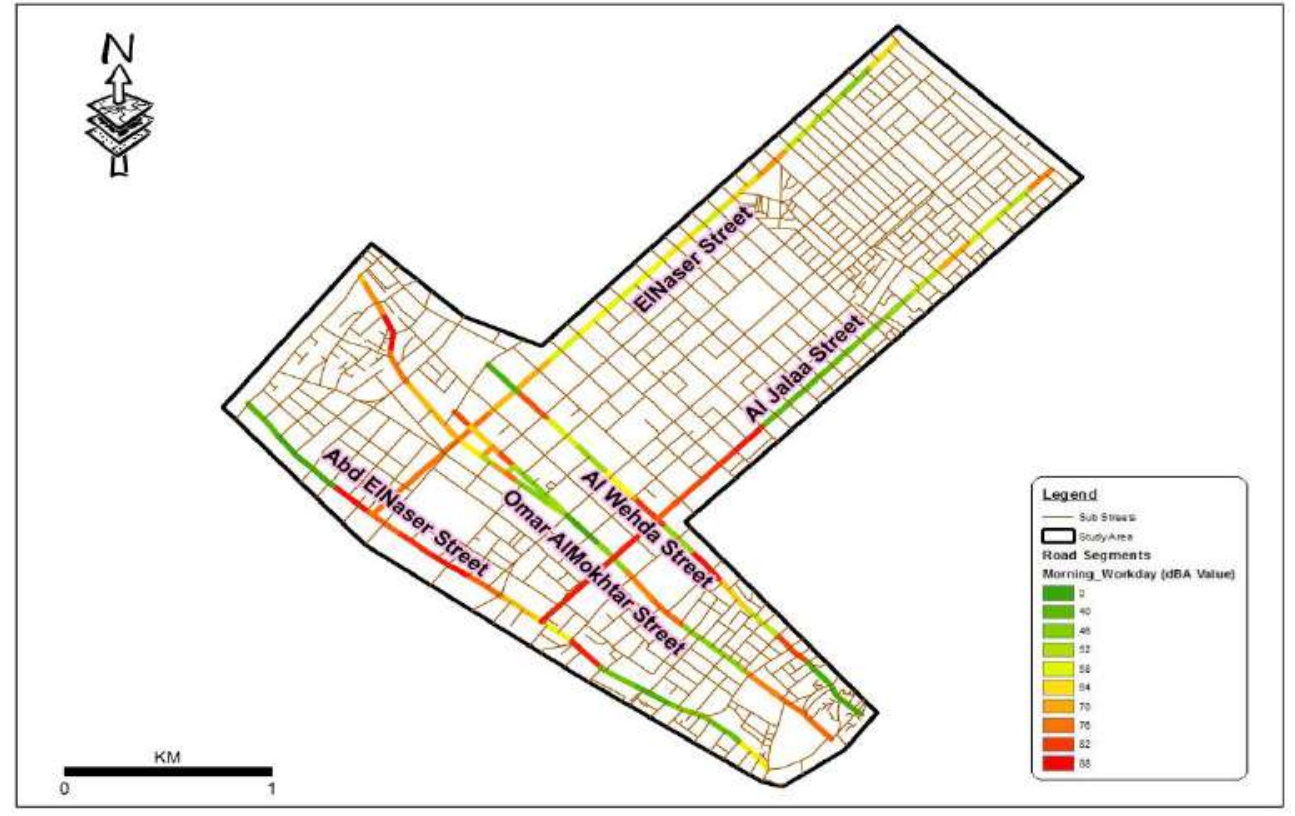

شكل ؛ . تصنيف الشوارع على أساس معدلات الضوضاء في صباح أيام العمل. 


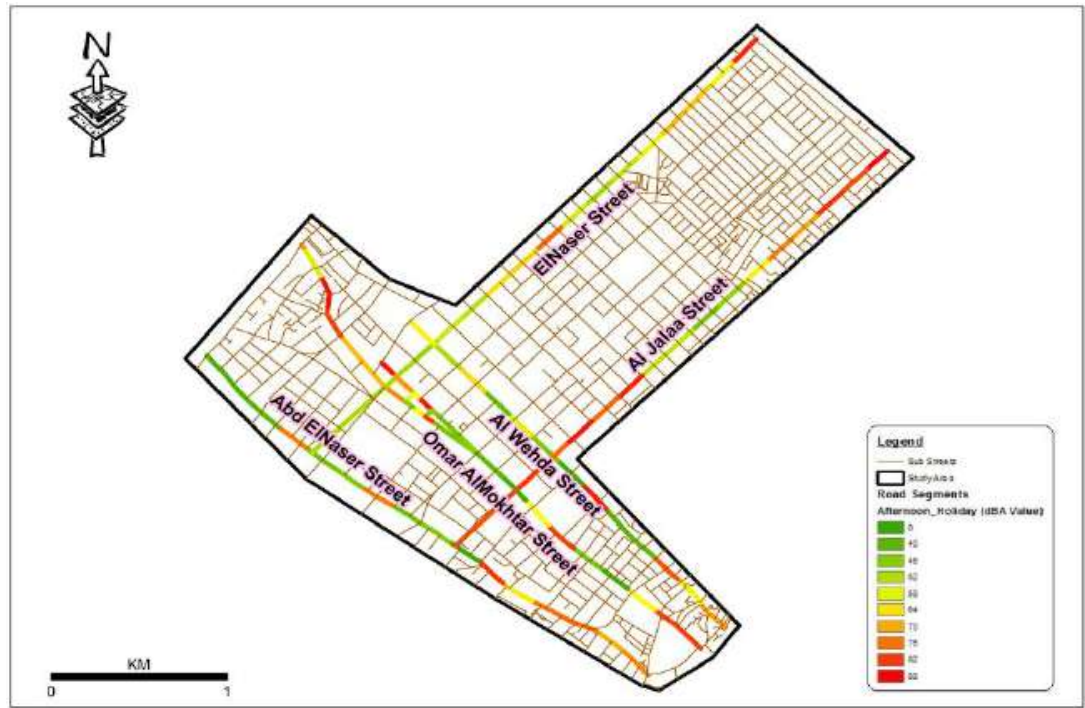

شكل ه. تصنيف الثوارع على أساس معدلات الضوضاء في ظهيرة أيام الإجازة.

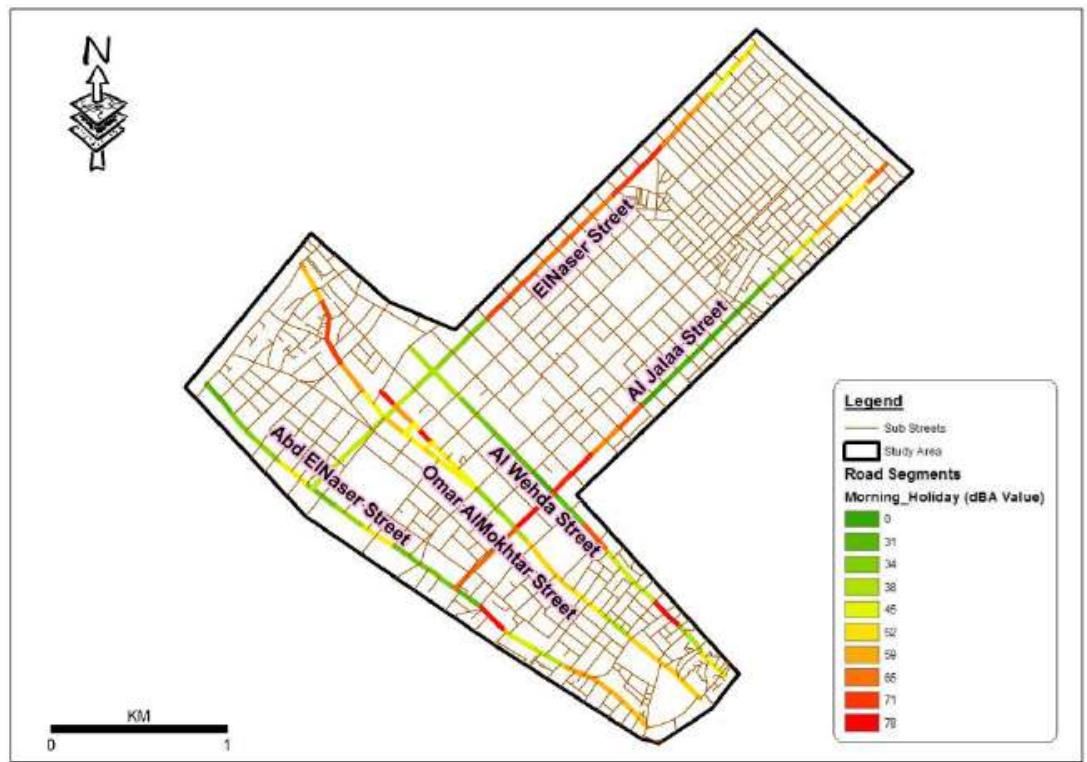

شكل 7.

الضوضـائي، حيث تم التدرج في الألوان من اللون

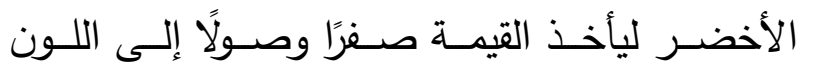
الأحمر الذي يحتل الأعلى في القيم واللون الأسود دال على المباني • ومن الجدير بالذكر أن المباني في المدينــة لا يـتم تجهيزهــا بمـواد خاصــة عازلــة
وفي منطقة الدراسـة هناك الكثير من المباني التي تتعـرض إلى الضوضـاء المروريـة، خصوصًا الواجهات المباشـرة لتلك الطرق، حيـث تم احتسـاب

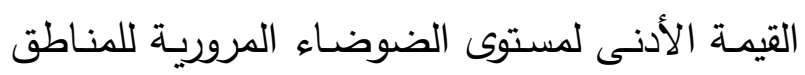
التي لا تقـع ضــن حدود انتشـار الصـوت والتلـوث 
7-r- الضوضـاء التـي تتعـرض لهـا واجهـات

$$
\text { المباني في صباح يوم إجازة }
$$

يظهر في هذه الفترة انخفـاض ملحوظ في

مستويات التلوث الضوضائي المروري حيث تراوحت

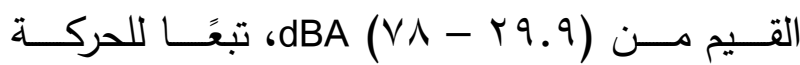

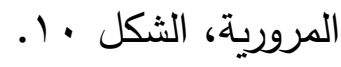

1- السكان النين يتعرضون إلى الضوضاء

يتعرض السكان في المباني المتاخمـة للطرق

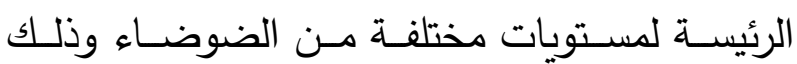
حسب موقع المبنى وارتفاعه ونوعية المواد الإنشائية التي اسـتخدمت في بنائـه، حيث يـنخفض مستوي الضوضاء بمعدل (0) لكل ارتفاع طابق واحد (זّم) [• "] فالسكان الذين يسكنون في الطوابق العليا

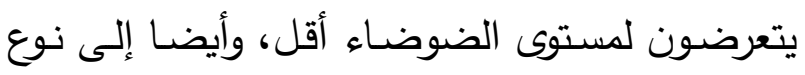
مـادة الرصـف الخاصــة بـالطريق وحركـة الهـرور عليها. ننوه هنا أن المباني الغير قريبة بشكل مباشر

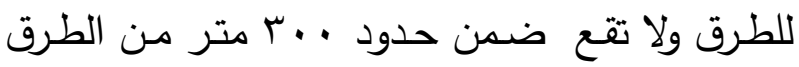
أعطيت القيمـة الأدنى لأنها غير داخلـة في نطـاق

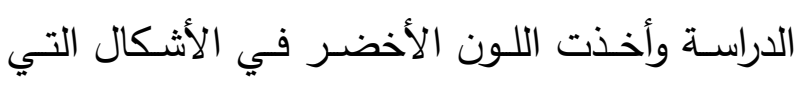

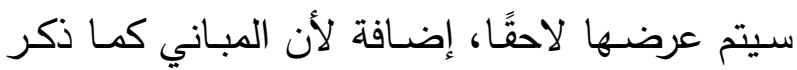

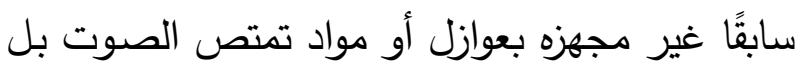

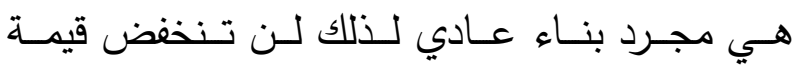
الضوضـاء أكثر مـن (r) dBA لكـل جـدار ســكـه

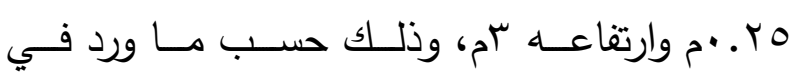
دراسات سابقة [ "']
للصوت، فقط يتم الاعتماد على الجدران الاعتيادية

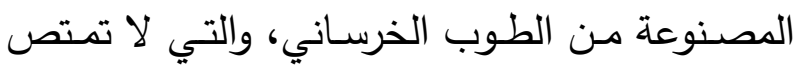
إلا جزء بسيط من حجم الضوضاء الصادر . T-r-1 الضوضـاء التـي تتعـرض لهـا واجهـات العباني في ظهيرة يوم عمل

تراوحت قيم الضوضاء المرورية في هذه الفترة

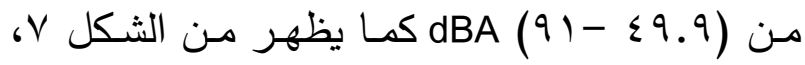

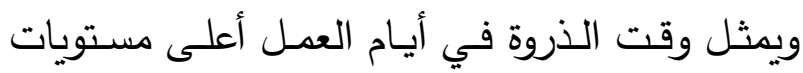
الضوضاء المرورية، حيث يلاحظ أن المباني الواقعة على المفترقات الرئيسـة مثل مفترق السرايا محاطـة باللون الأحمر ، وذلك دلالة على مستوى الضوضـاء العالي مقارنة ببعض المحاور الداخلية. r-r-r الضوضـاء التـي تتعـرض لهـا واجهـات المباني في صباح يوم عمل

تراوحت قيم الضوضـاء في هذه الفترة مـن

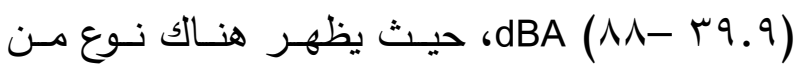
الانخفاض في قيم الضوضـاء في بعض المناطق، بينما ترتفع في نطاقات أخرى، والتي تكون متاخمـة لحركة مرورية كبيرة الثكل ^. r-r-r الضوضـاء التـي تتعـرض لهـا واجهـات المباني في ظهيرة يوم إجازة

تراوحت قيم الضوضـاء في هـذه الفترة مـن

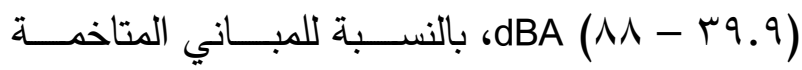
للأسواق لم تتغير الحالة المرورية كثيرًا، لذلك لم نلاحظ باله تغير كبير في مستويات الضوضاء، الثكل 9. 
7-r-1 السكان الذين يتعرضون إلى الضوضلاء في لمستويات ضوضـاء عالية تبعًا لطبيعة العوامل التي

$$
\text { تزيد من فرص تزايده، الشكل ا ا. }
$$$$
\text { ظهيرة يوم عمل }
$$

r-r-r السكان الذين بتعرضون إلى الضوضلاء في ترمب

$$
\text { صباح يوم عدل النين لتعرن }
$$

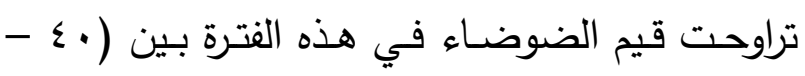
dBA (^ᄉ أيضًا لوحظ اختلاف حسب موقع البناء ويظهر ذلك واضتح في الشكل r I .

تراوحت مسـتويات الضوضـاء المروريـة التي يتعرض إليها السكان في هذه الفترة من (، (0 - (9) ويمثـل وقـت الـذروة فـي أيـام العمـل أعلـى dBA مستويات الضوضاء المرورية، حيث يتعرض السكان

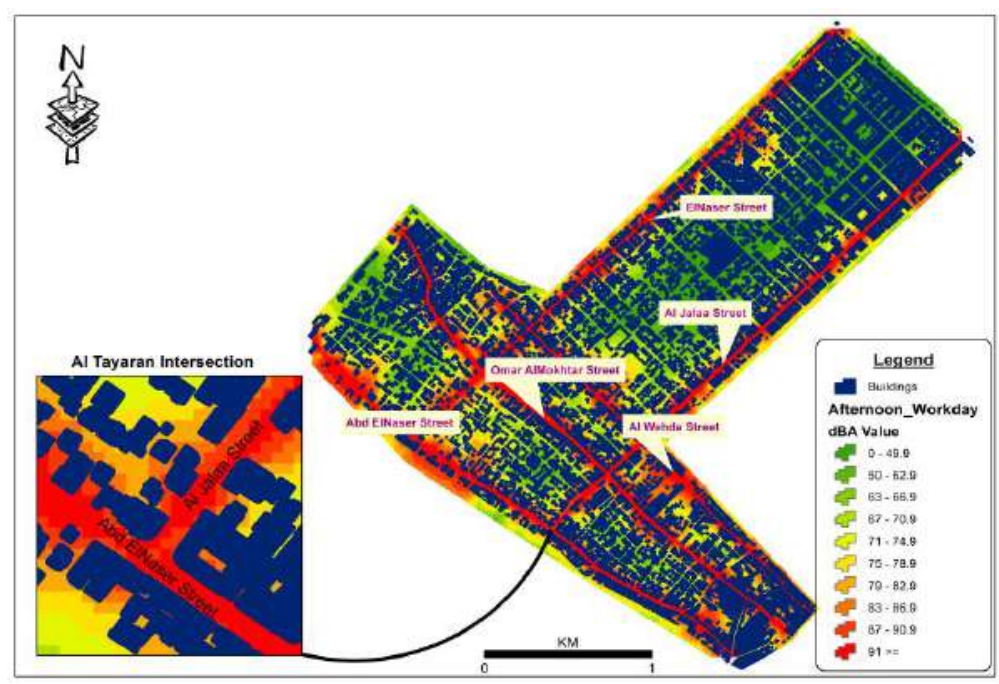

شكل V. طبيعة توزيع الضوضاء على واجهات المباني في ظهيرة يوم عمل.

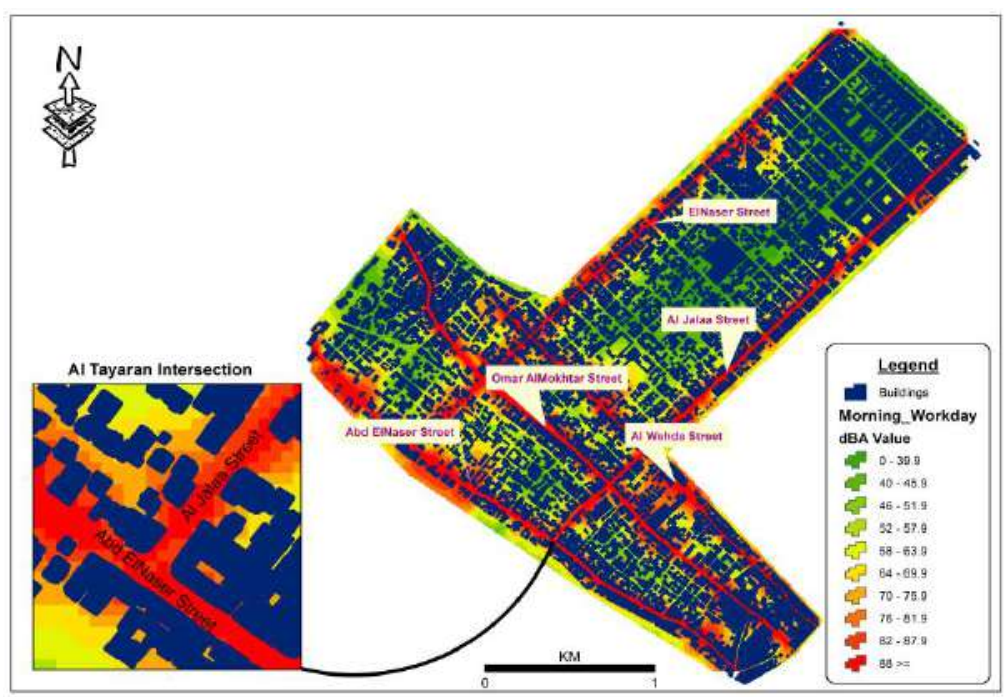

شكل ^. طبيعة توزيع الضوضاء على واجهات المباني في صباح يوم عمل. 


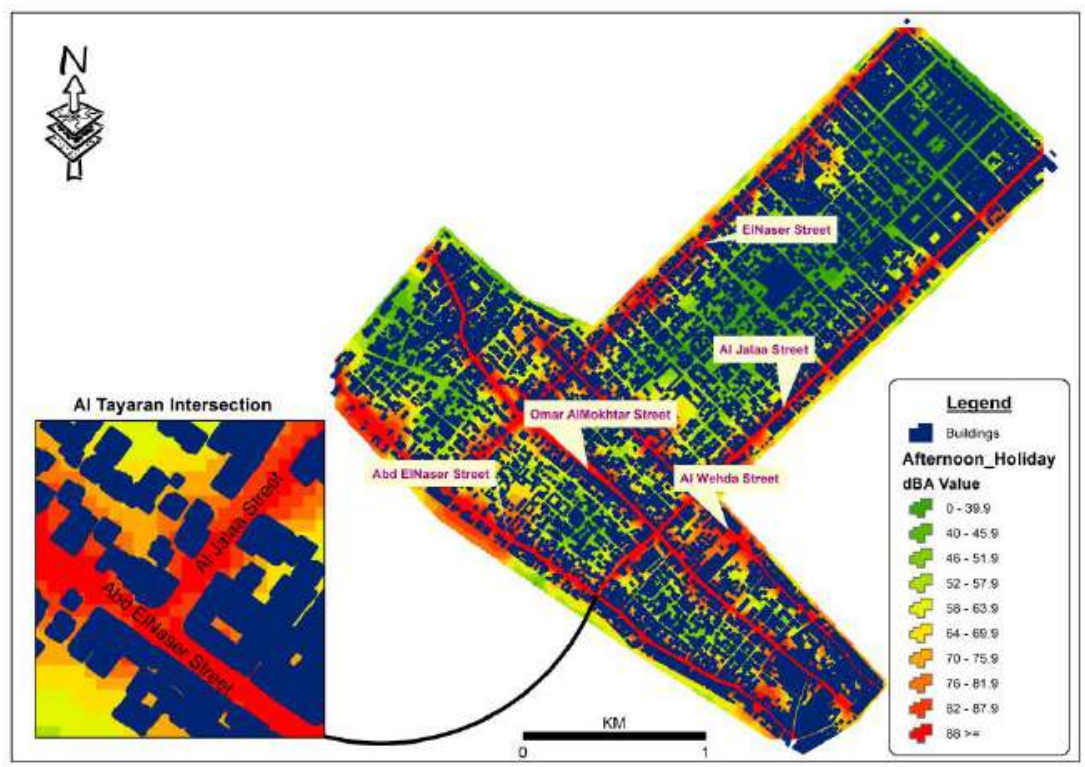

شكل 9 ـ طبيعة توزيع الضوضاء على واجهات المباني في ظهيرة يوم إجازة.

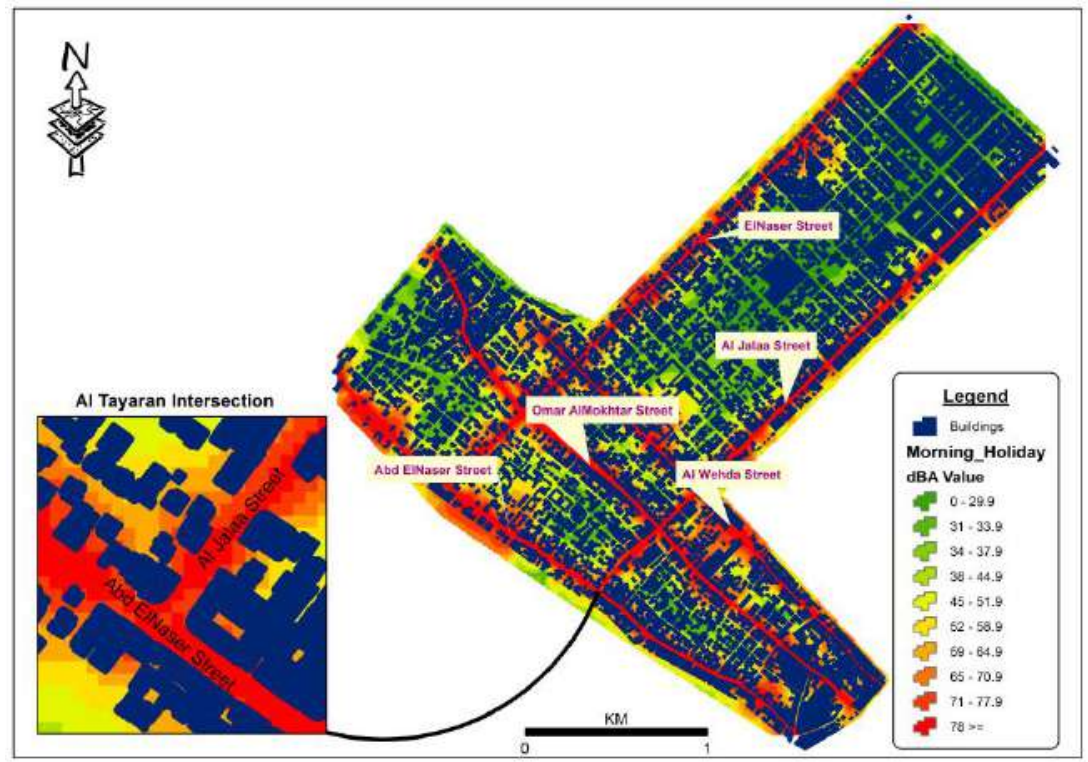

شكل ـ ا ـ طبيعة توزيع الضوضاء على واجهات المباني في صباح يوم إجازة. 


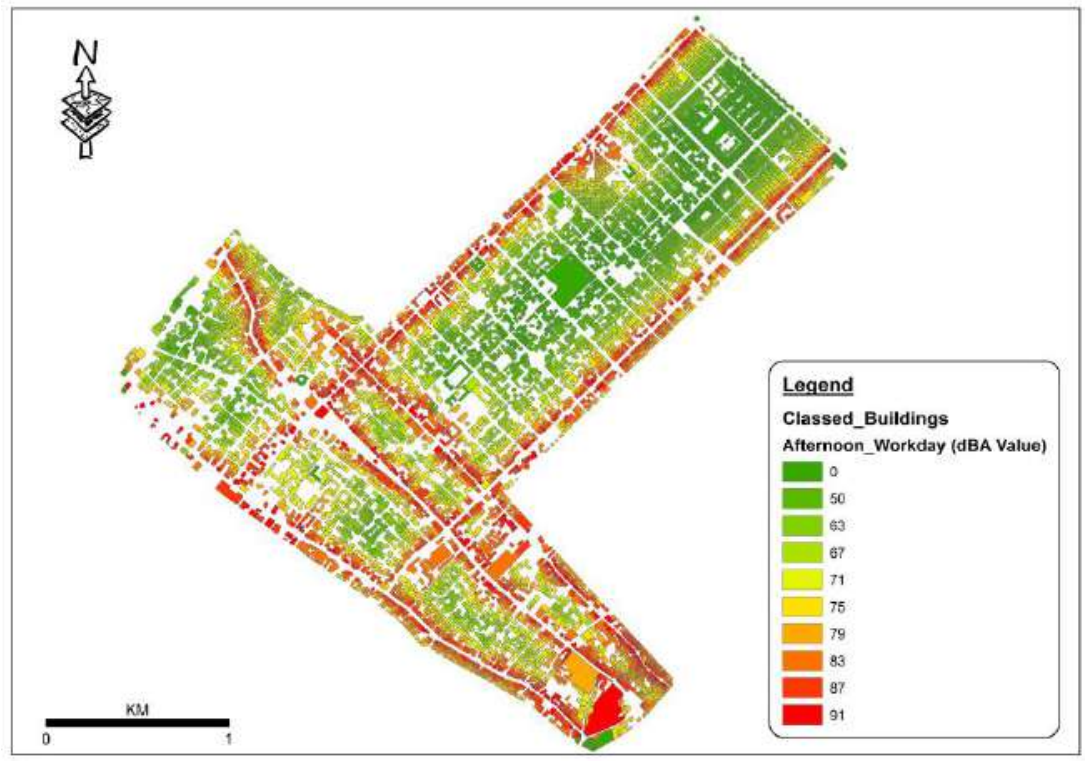

شكل 11 ـ تصنيف المنازل السكنية حسب تعرضها للضوضاء في ظهيرة يوم عمل.

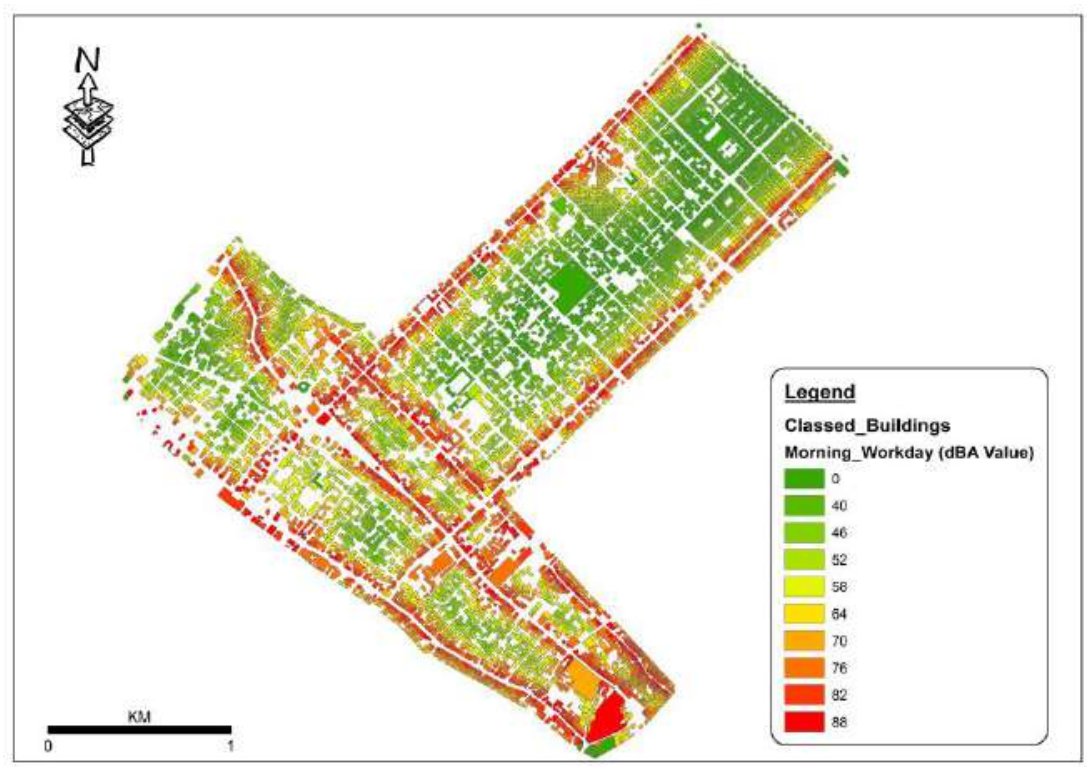

شكل r 1 ـ تصنيف المنازل السكنية حسب تعرضها للضوضاء في صباح يوم عمل.

مـن ناحية وجودهـا بجوار أسـواق، لذلك يبقى تأثير الضوضـاء المروريـة في السـكان كمـا هو في تلك المناطق، بخلاف المباني التي تقع بجوار مؤسسات حكوميـة ومـدارس وغيـره فلـوحظ أن التأثير فيها قد 7-r-r السكان الذين يتعرضون إلى الضوضلاء في ظهيرة يوم إجازة

نلاحظ أن قيم الضوضـاء المروريـة لم تختلف في بعض المنـاطق نظرًا لموقعها وأهميتها المكانيـة 
قرب المحاور المؤدية إلى جهات العمل الرسمية كافة

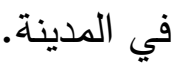

7ظهيرة يوم إجازة

شكل توزيع الضوضاء في ظهيرة يوم إجازة تبدو

الأقل حدة في انتثـارها من أيام العمل، لكن ترتكز

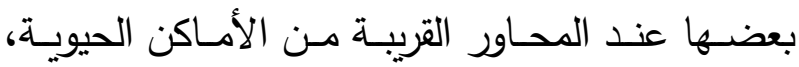

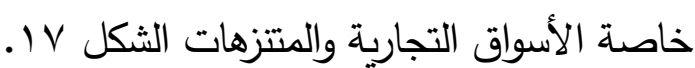
7 - $1-\{$ طبيعـة انتشـار الضوضـاء المروريـة فـي صباح يوم إجازة

يثــير الثــكل 11 إلــى طبيعـــة انتشـــار

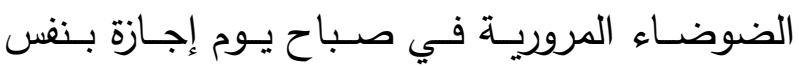

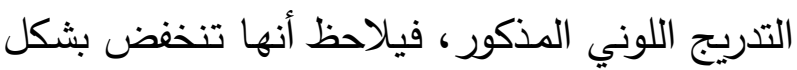

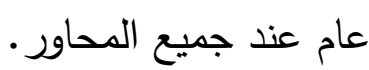

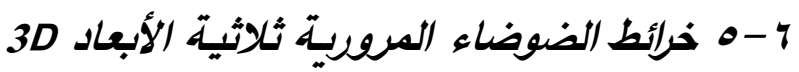

Noise Maps

تمثـل الأشـكال مـن 9 ا وحتى لب خـرائط

ثلاثية الأبعاد، تمثل حال انتشار الضوضـاء المرورية على المباني السكنية المحاذية للشوارع ، حيث تبين

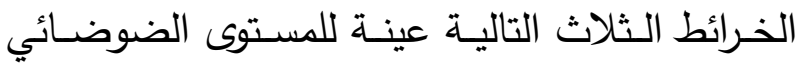
الذي تتعرض لـه المباني السكنية في أحد الأوقات

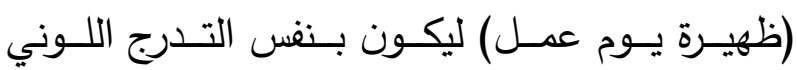
(الأحمر - أكثر شدة) حيث وصلت إلى لى لون و(الأخضر - الأقل شدة) حث وصلت إلى هنى .9.9 . $\mathrm{dBA}$
انخفضت قيمته، وفي هذه الفترة تراوحت القيم من .$d B A(\wedge \wedge-\varepsilon \cdot)$ 7-r-z السكان الذين يتعرضون إلى الضوضاء في صباح يوم إجازة

فـي هـذه الفتـرة يتعـرض السـكان في تلـك

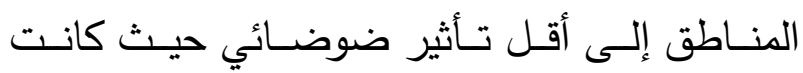
النتيجة بين (اس - dBA

1 - ك طبيعة انتشار الضوضاء المرورية نهاًًا

توضـح هـذه الخـرائط طبيعـة توزيـع وانتشــار ظاهرة الضوضـاء المروريـة في أنحاء منطقة الدراسـة نهـارا، حيـث منطقــة الدراسـة تركـزت في الثـوارع

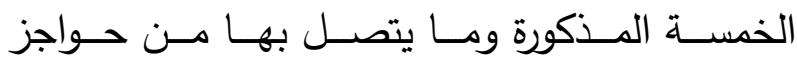

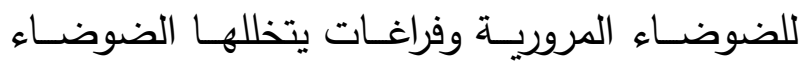
ليقطع أكبر مدى له على النطاق الأقصى . . بام. 7- - إ طبيعـة انتشـار الضوضـاء المروريـة فـي ظهيرة يوم عمل

يظهر الثكل 10 طبيعة انتشار هذه الظاهرة في ظهيرة يوم عمل، حيث تم اعتماد التدرج اللوني نفسـا من الأحمر أكثر حدة حتى الأخضر الأقل حدة. r- r- طبيعـة انتثـار الضوضـاء المروريـة فـي صباح يوم عمل

يوضـح الثـكل 7 احالـة انتثــار الضوضــاء المرورية في صباح أيام العمل خلال الثوارع الخمسة

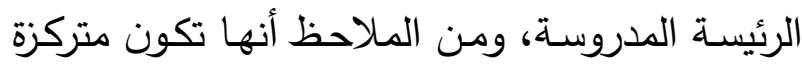




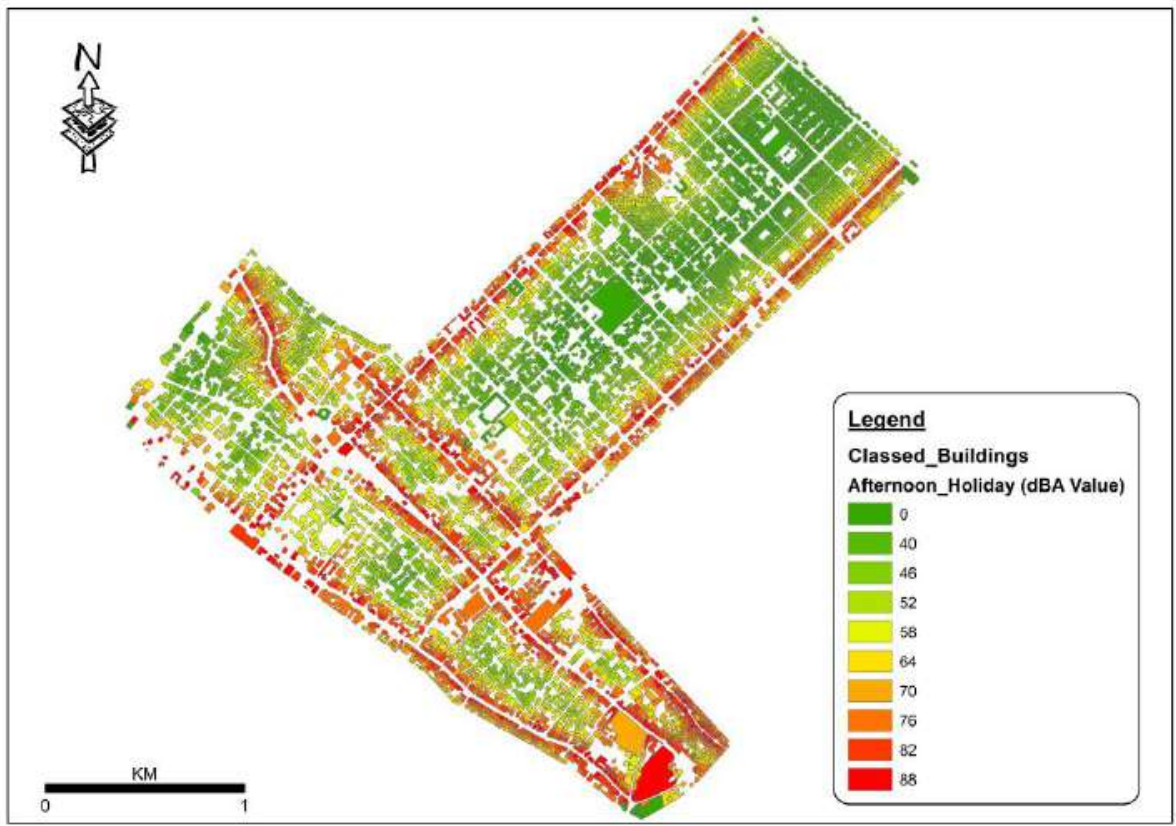

شكل ب 1 ـ تصنيف المنازل السكنية حسب تعرضها للضوضاء في ظهيرة يوم إجازة.

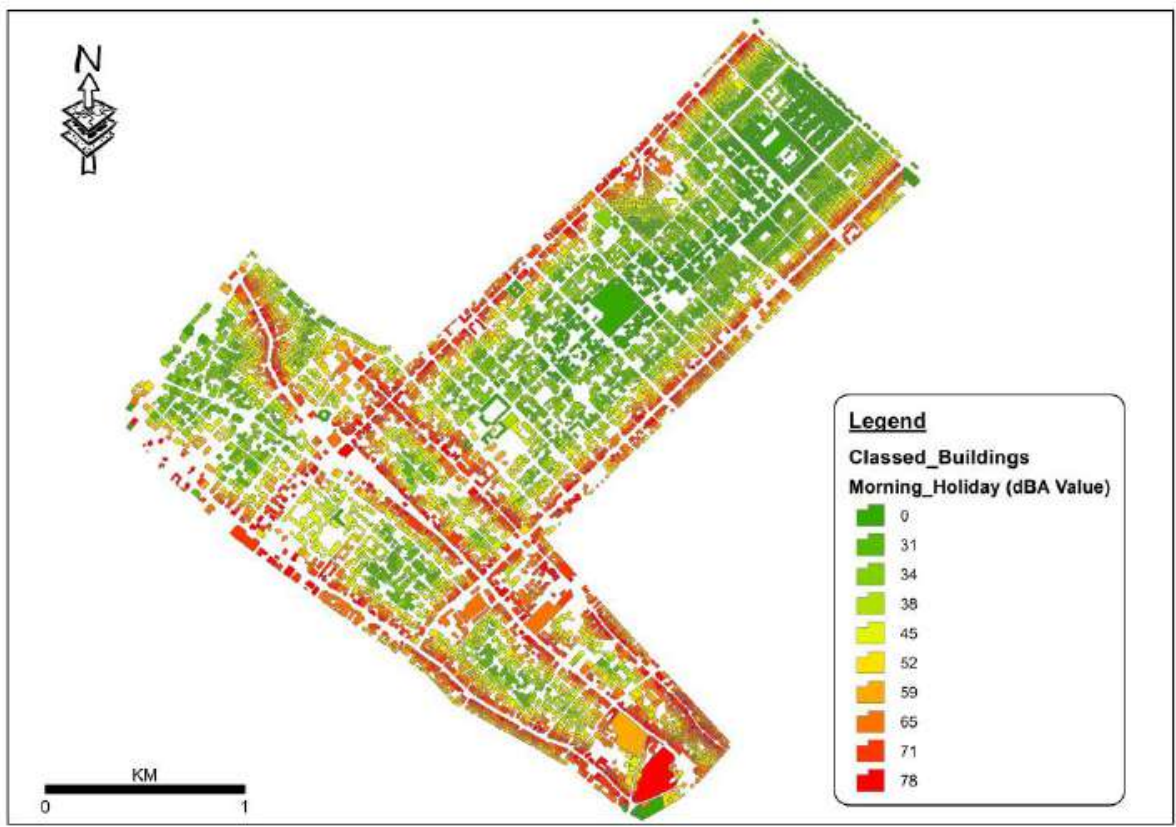

شكل ؛ 1 ـ تصنيف المنازل السكنية حسب تعرضها للضوضاء في صباح يوم إجازة. 


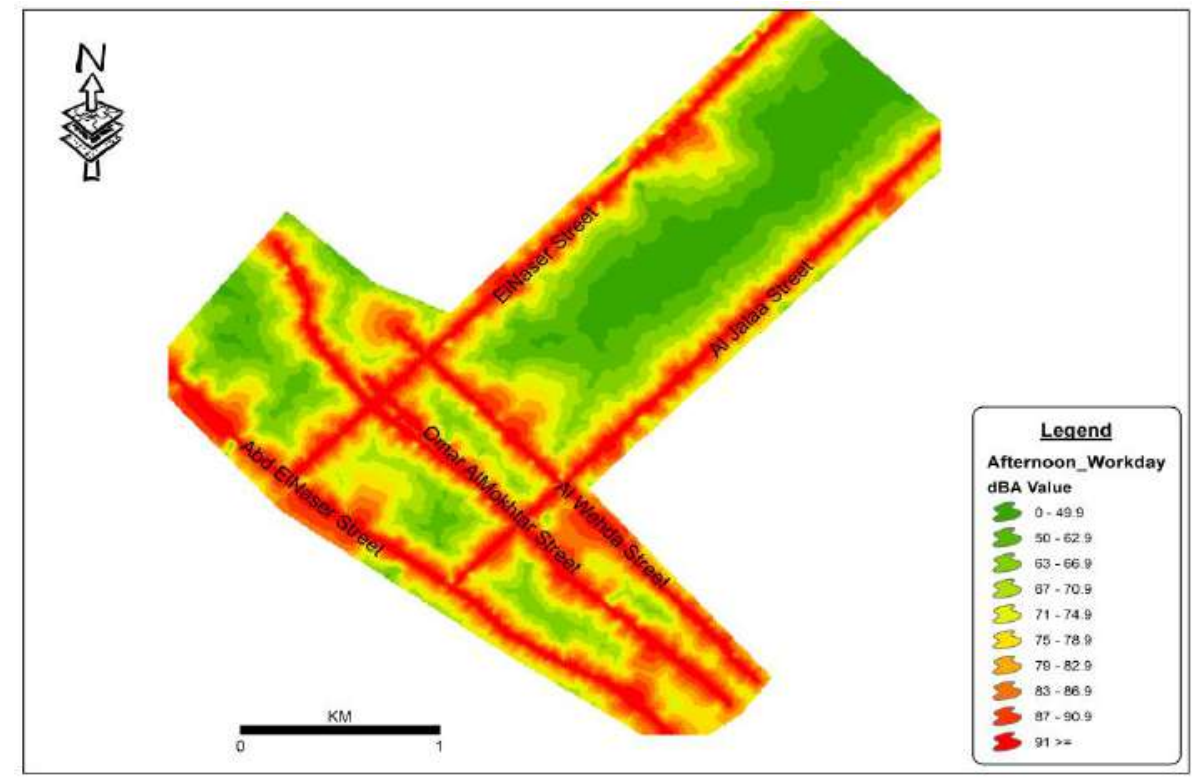

شكل ه 1 ـ طبيعة انتشار الضوضاء في ظهيرة يوم عمل.

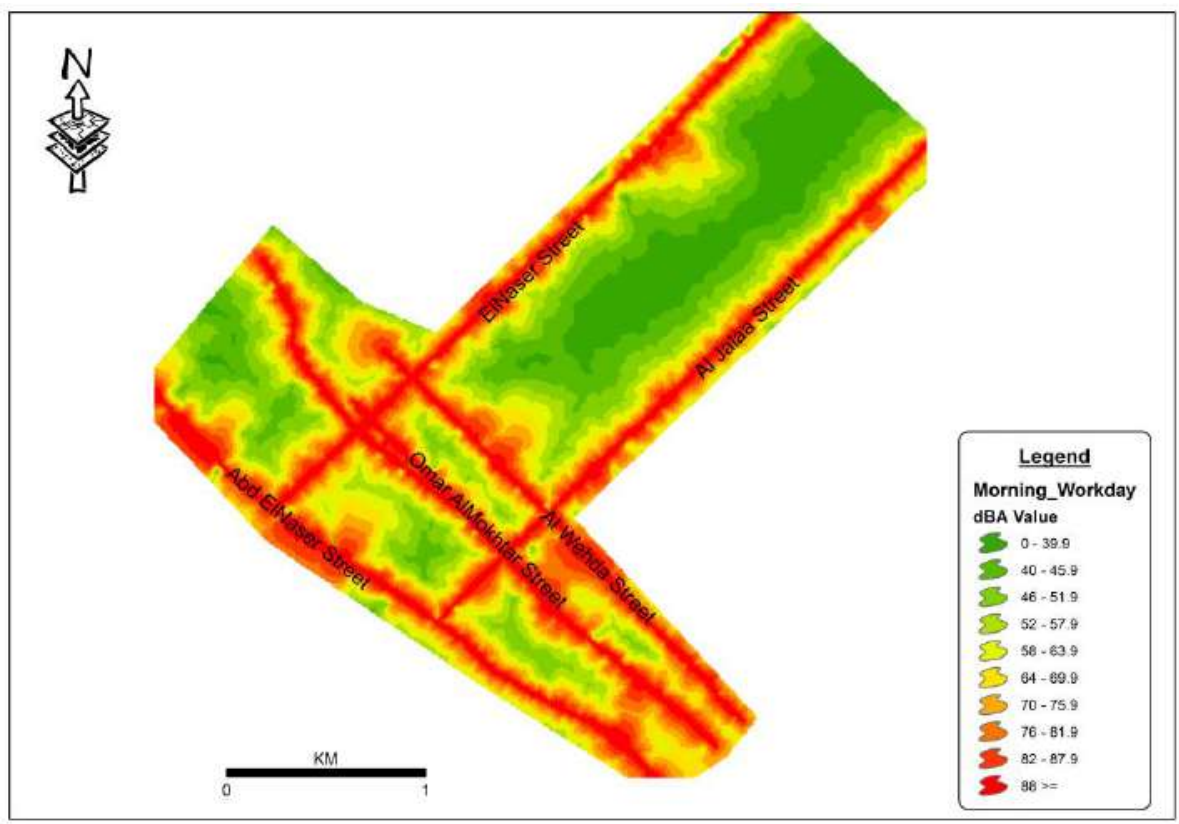

شكل 17 ـ طبيعة انتشار الضوضاء في صباح يوم عمل. 


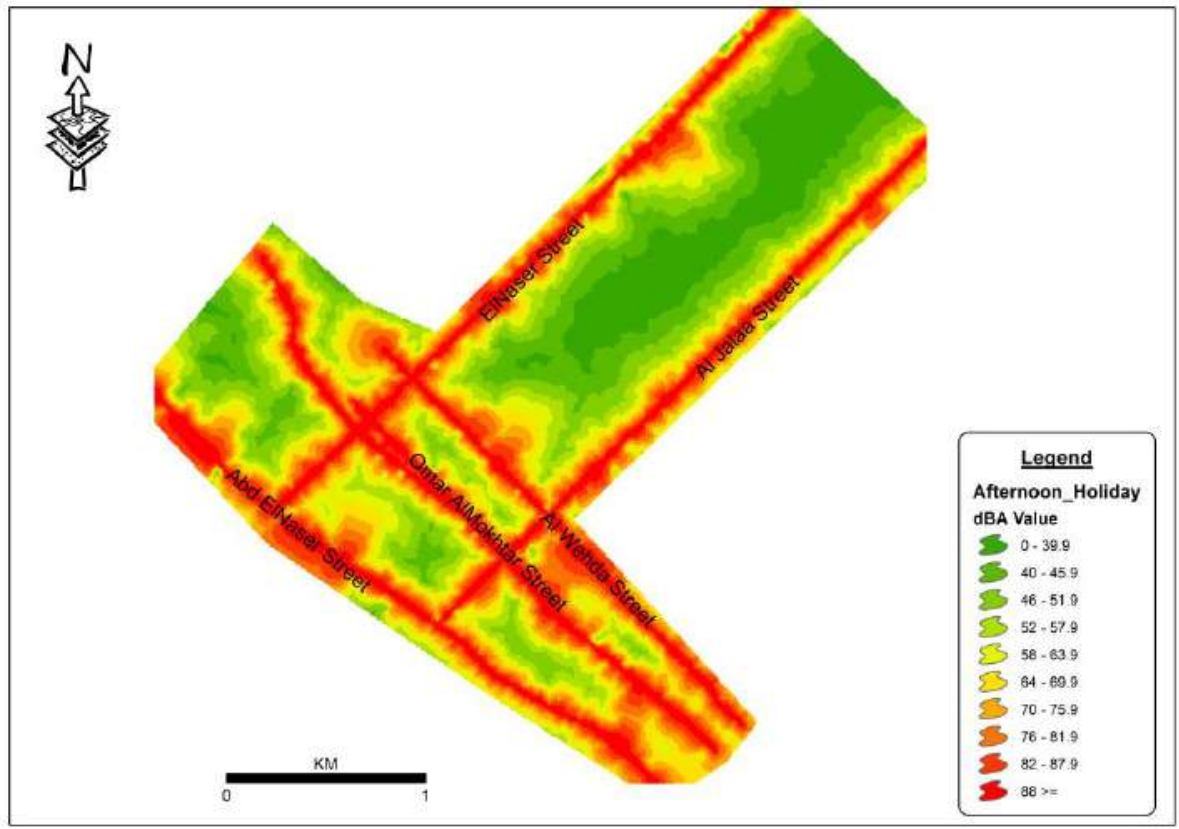

شكل IV . طبيعة انتشار الضوضاء في ظهيرة يوم إجازة.

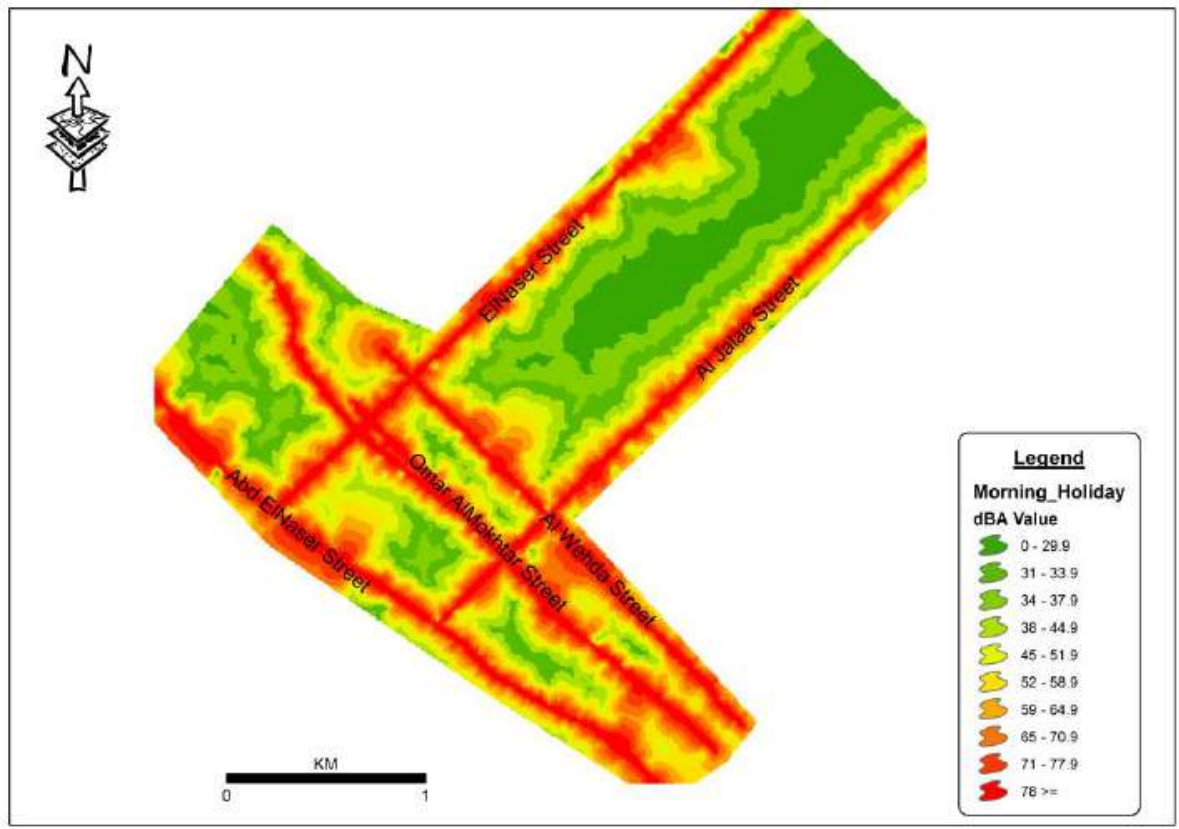

شكل 11 اـ طبيعة انتشار الضوضاء في صباح يوم إجازة. 


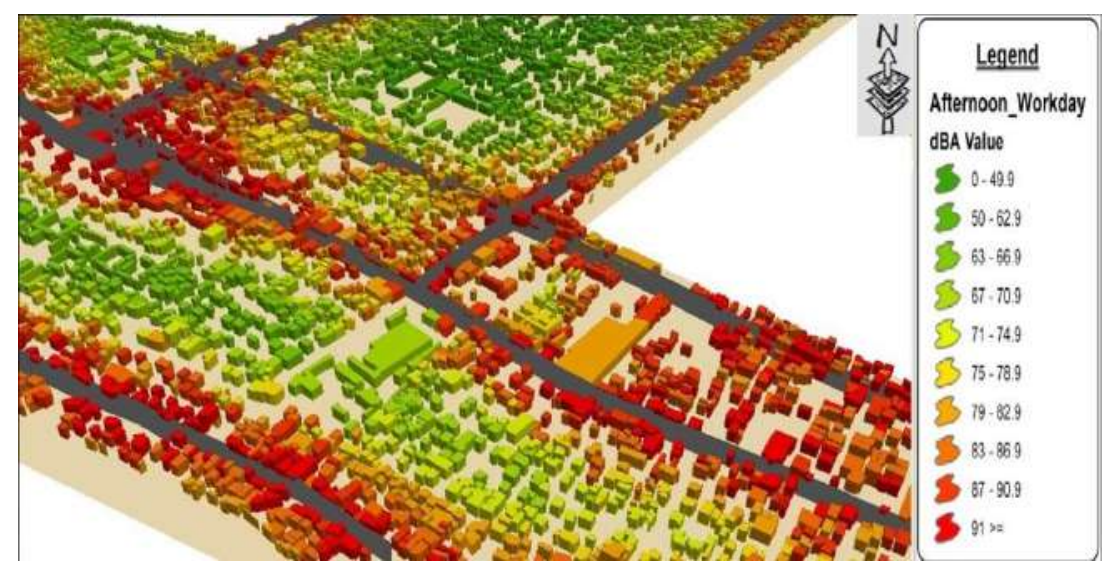

شكل 9 ـ مقطع 1 يبين طبيعة انتشار الضوضاء المرورية على المباني السكنية المحاذية لها-منطقة الاراسة.

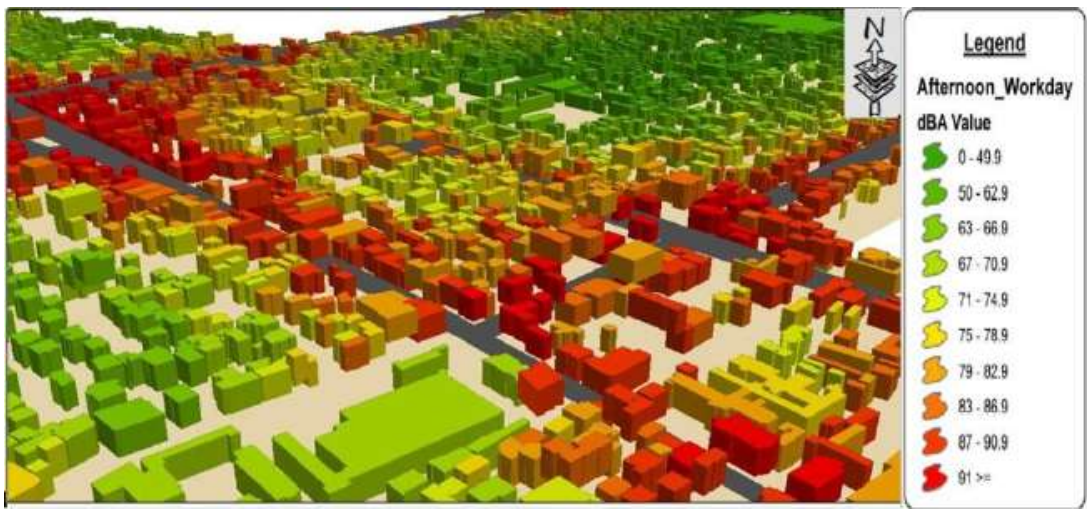

شكل . . مقطع ץ يبين طبيعة انتشار الضوضاء المرورية على المباني السكنية المحاذية لها-وسط منطقة الاراسة.

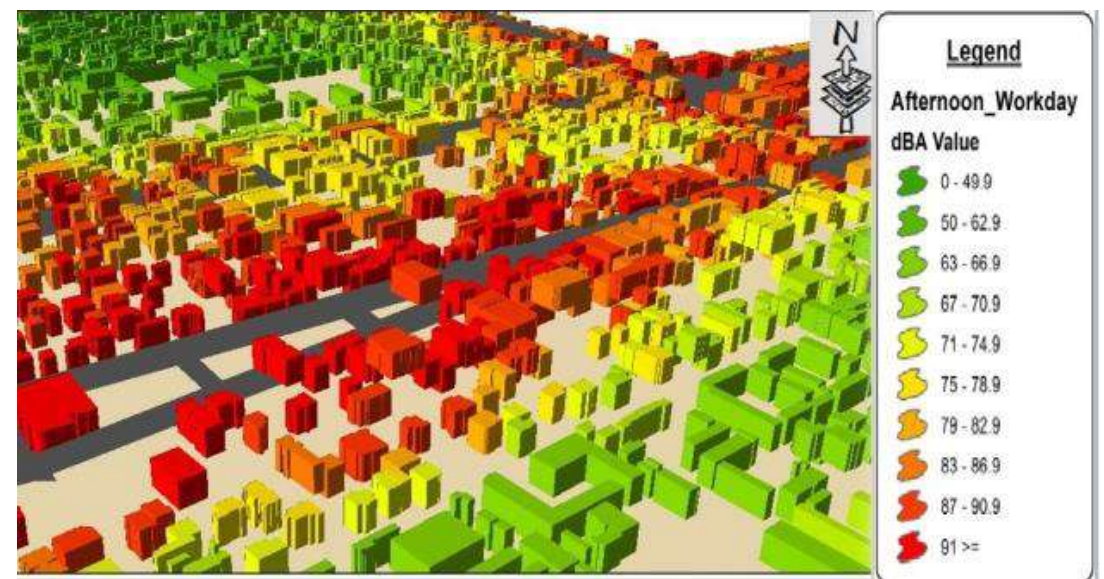

شكل اץ ـ مقطع ץ يبين طبيعة انتثار الضوضاء المرورية على المباني السكنية المحاذية لها- شارع عمر المختار (منطقة (الجندي المجهول). 
المبـاني السـكنية على أسـاس تعرضـها للضوضــاء

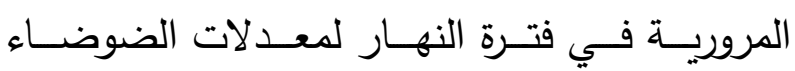
المرورية التي تزيد عن المعدلات المسموح به في كل لهرول فترة مـن هذه الفترات حسـب المواصـفات الصـحية

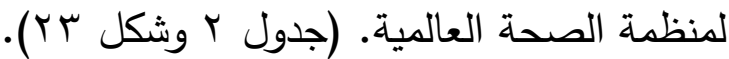

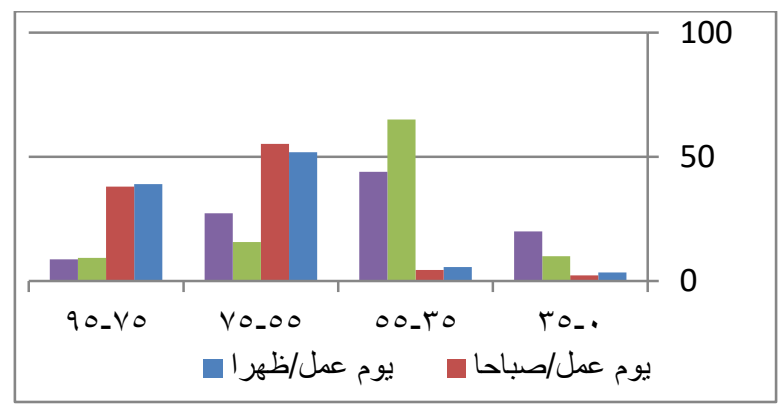

شكل r.r. توزيع نسب مساحة منطقة الاراسة حسب انتشار الضوضاء المرورية فيها.

جدول r. نسب المباني المتعرضة للضوضاء المرورية في

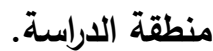

\begin{tabular}{|c|c|c|}
\hline \multicolumn{2}{|c|}{ المباني المتعرضة للضوضاء المرورية } & \multirow[t]{3}{*}{ الفترة } \\
\hline \multicolumn{2}{|c|}{ dBA >55 نهارا } & \\
\hline عدد & نسبة \% & \\
\hline 11226 & 98.9 & يوم عمل/ظهرا \\
\hline 11226 & 98.9 & يوم عمل/صباحا \\
\hline 11226 & 98.9 & يوم إجازة/ظهرا \\
\hline 5392 & 47.5 & يوم إجازة/صباحا \\
\hline
\end{tabular}

1-7-r تأثير الضوضاء الهرورية على السكان

وصل عدد السكان في منطقة الدراسة حوالي I I S V . . تعرضهم لدرجات الضوضاء المرورية خلال ساعات النهار والليل، جدول r وشكل گr يبينان طبيعة هذا צtatistic Results 1 - نتائج إحصائية

تم عمل تحليل إحصـائي مبسّط من خـلال برنامج ArcGIS9.3 باستخدام أداة الاستعلام الدكاني للحصــول علــى بعـض النسـب الرئيسـة لفتـرات الضوضاء المرورية وعلاقتها بكل من: 1- مساحات انتشار الضوضاء المرورية.

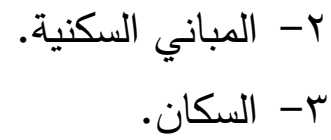

7-7 - أثثير الضوضاء المرورية على منطقة الدراسة

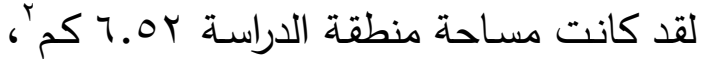
وتم تصـيف مسـاحة المنطقـة حسب تعرضـها إلى درجات الضوضاء المروري تدريجيا, جدول ا و شكل

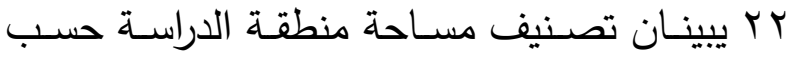
انتشـار الضوضـاء المروريـة نهارا في جميع الفترات على أساس حدتها.

جدول 1. تصنيف مساحة منطقة الاراسة حسب انتشار الضوضاء المرورية.

\begin{tabular}{|c|c|c|c|c|}
\hline \multicolumn{4}{|c|}{ تصنيف مساحة منطقة الاراسة حسب انتشار } & الضوضاء \\
\hline $0-35$ & $35-55$ & $55-75$ & $75-95$ & $\mathrm{dBA}$ \\
\hline 3.5 & 5.65 & 51.85 & 39 & يوم عمل/ظهرا \\
\hline 2.3 & 4.50 & 55.2 & 38 & يوم عمل/صباحا \\
\hline 10 & 65 & 15.70 & 9.3 & يوم إجازة/ظهرا \\
\hline 20 & 44 & 27.28 & 8.72 & يوم إجازة/صباحا \\
\hline
\end{tabular}

7-7-r تأثير الضوضاء المرورية على المباني لقد احتوت منطقة الدراسة قرابة . هب 11 مبنئً سـكنيًا بجميـع ارتفاعاتهـا، حيـث تـم تصـنيف هـذهـ 
V - مناقشة وتحليل النتائج

إن النتائج السـابقة تعكس حالـة متفاوتـة بـين

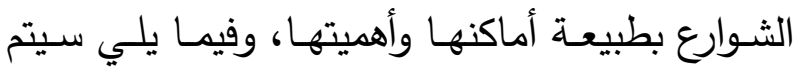

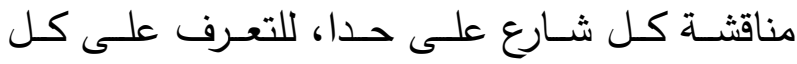
تفاصيله بالنسبة للضوضاء المرورية ومدى انعكاس هذه الظاهرة عليه.

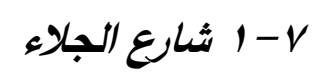

يتميـز شـارع الجـلاء في كونـهـ أحـد الطـرق الرئيسـة، الذي يربط مدينـة غزة مـع محافظـة شمال

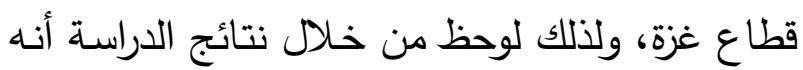

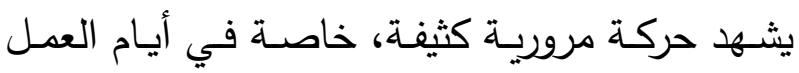

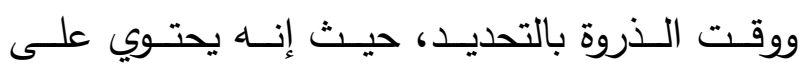
اتجاهين عريضين في كل مسار مروري، إضـافة إلى تكدس الأبراج السكنية العاليـة على جانبيـه، وتباين مناسيب الثـارع طوليـا، والتي تمنـع تشتت وانتشـار

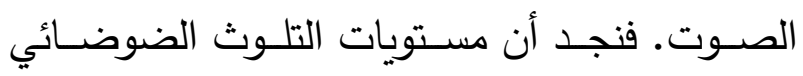
المروري علي مقاطع الشـارع كافة كانت تتراوح بين

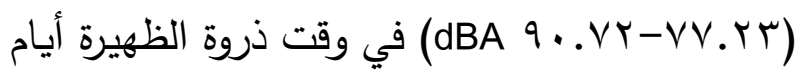

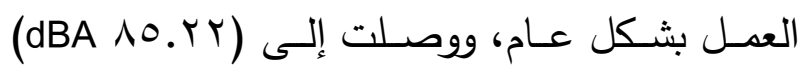
كمتوسط حسابي.

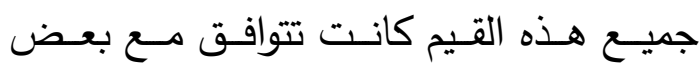
الدراسـات ذات العلاقة، حيث أشـارت دراسـة التقيّم المـروري [']" إلى أن عدد المركبـات التي تمر في في في بعض المحاور تزيد سرعاتها في محاور أخرى أكثر لئر من شارع الجـاء نفسه ، وأن سرعاتها ينعكس أثرها
التصنيف الذي يعكس حالة سيئة ومعاناة ملموسة

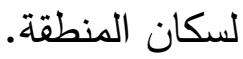

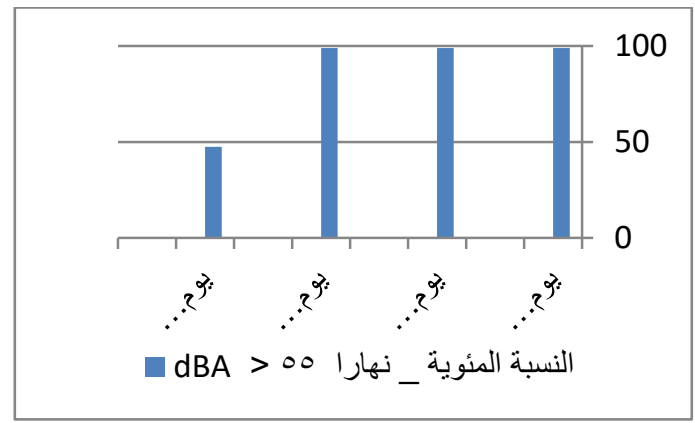

شكل بr r . نسب المباني المتعرضة للضوضاء المرورية في منطقة الدراسة.

جدول r. نسب السكان المتعرضين للضوضاء المرورية في

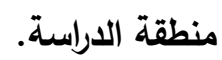

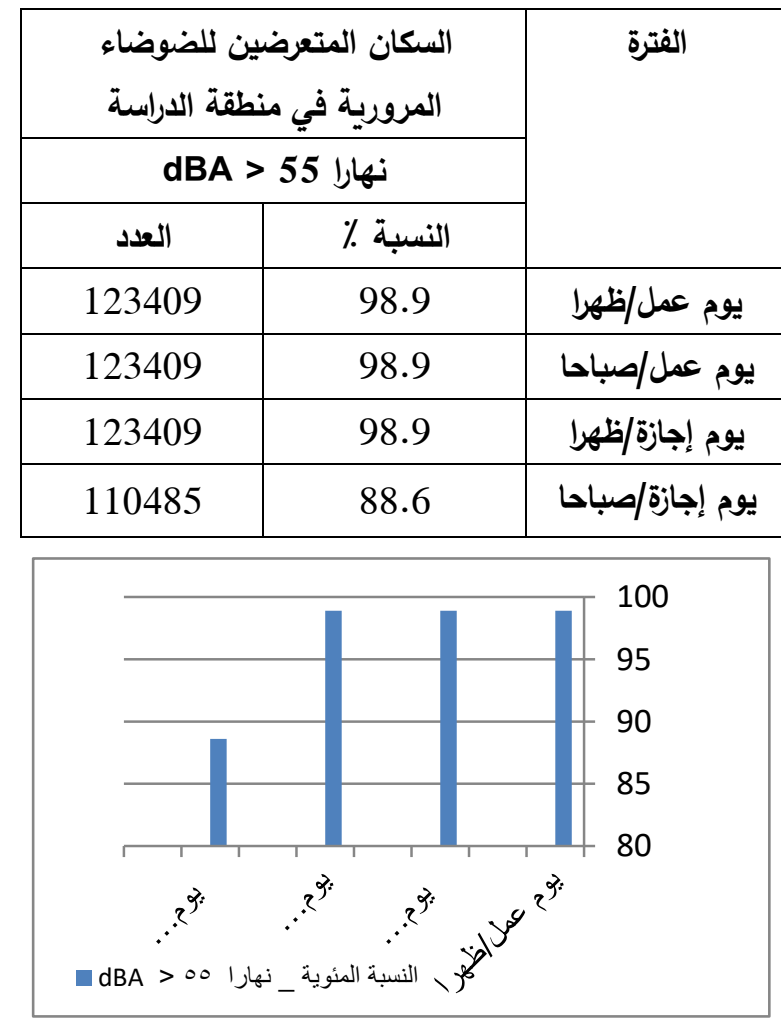

شكل § ؟. نسب السكان المعرضين للضوضاء المرورية في منطقة الدراسة. 
بعض القيم المتوافقة في بعض الدقاطع، والبعض اختلف نتيجة التطورات التي حدثت في الدكان مثل منطقة السرايا(مجمع السرايا) تحديدًا والتي تعرضت فيت التكان

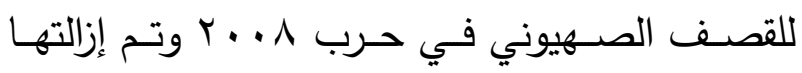
لاحقا فأدى هذا إلى فرصة انتثار اكبر للضوضاء المرورية وسرعة تثتت لها. كذلك نجد مثلا في وقت الذروة (ظهيرة أيام

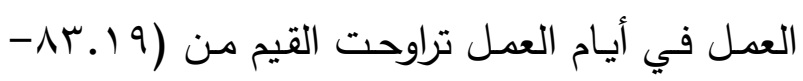

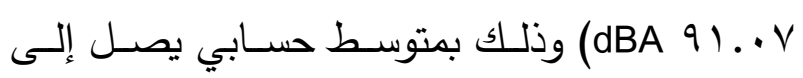

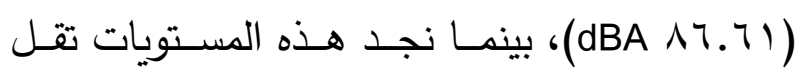
بنسبة بسيطة في فترة الصباح في أيام العمل، حيث اندان تعمل الحركة المرورية على نقل المواطنين لأماكن الماكن

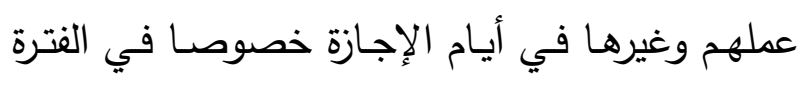
الصباحية التي تشهـل بعض القطاعات في الثـارع

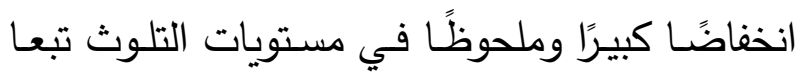
للحركة المرورية. ولكن في فترة الذروة، يلاحظ أنها

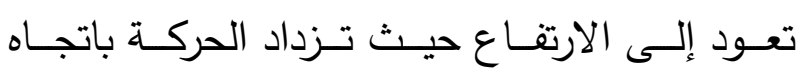

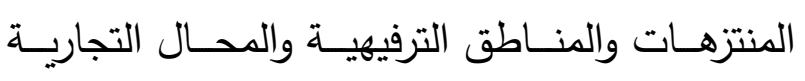
الموجودة علي طول الشارع.

r-v شارع الوحدة

شارع الوحدة هو الموازي من الجهة الثمالية

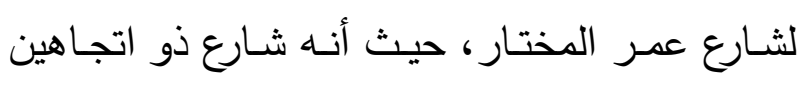
ولكن بعرض أصغر من شارع عمر المختار. من خلال النتائج يلاحظ أن أعلى مستويات

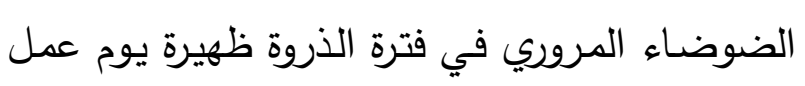

في طبيعة التدفق المروري الحاصل، والذي يؤثر بشكل مباشر في الضوضاء المرورية. r-v يربط هذا الثارع شرق مدينة غزة بغربها، ومما يميز هذا الثـارع عن غيره من الثوارع أنه يعتبر

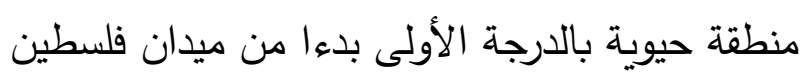
(موقف السيارات، وسوق الزاوية، وبنوك تجارية مثل بلدئ

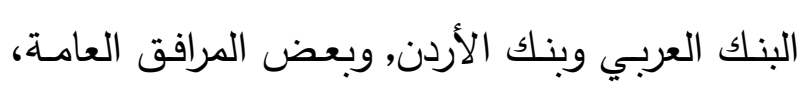
مثل مبنى البلدية ومركز الثرطة) إلى (مفترق

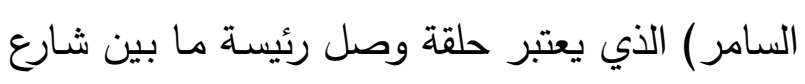

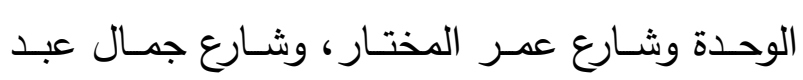

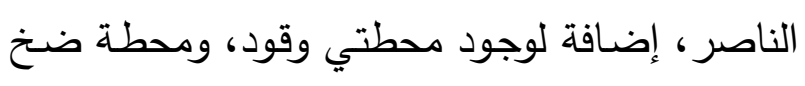
للصرف الصحي هناك، وأيضا بعض المرافق العامة مثل منتزه البلدية ووزارة الاتصالات والبريد القريبتان من الففترق الذي يليه (مفترق السرايا) والذي يحيطه بعض الأبراج على طول امتداد الثارع حيث الفنادق السكنية ومكاتب العقارات وغيره، ومن ثم يمتد الثارع الثارع وصـولا إلى منطقة الجندي الدجهول التي تعتبر منطقة ترفيهية وتجارية.

كل ما سبق ذكره كان بمثابة عوامل ومؤثرات

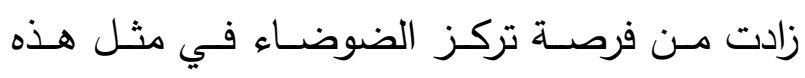

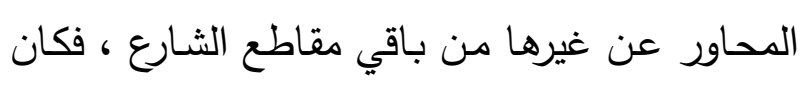

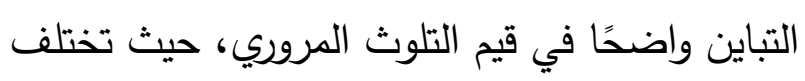
ما بين الارتفاع والانخفاض، سواء في أيام العمل أو الو التوري،

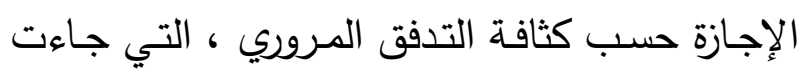

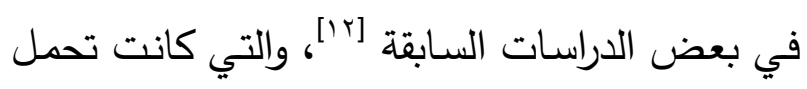


للإنسان والتي حددتها منظمة الصحة العالمية (0ء.dBA $(0$.

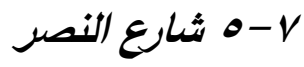

هو الشارع الموازي لثـارع الجلاء من الناحية الغربيـة، حيث يربط مدينـة غزة مـع محافظـة شمال

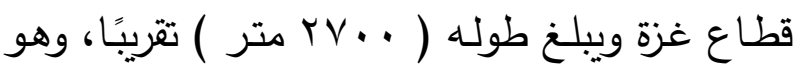

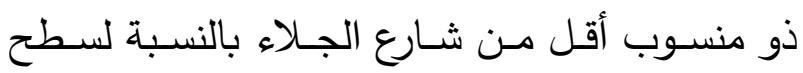

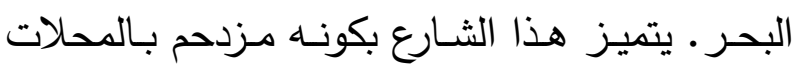
والمراكز التجاريـة المختلفة، والأبراج السكنية العالية إضـافة لوجود عدة مستشفيات وعدد من المـارس

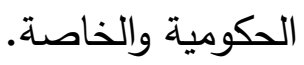

تلك العوامل السـابقة تعمل على زيادة الحركة

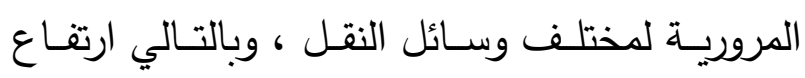

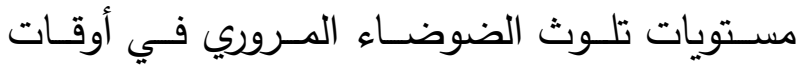

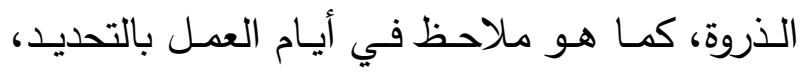

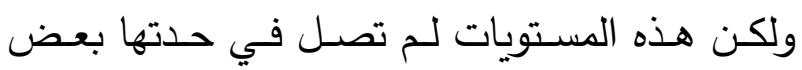
الثوارع موضوع الدراسة ، خاصة شارع الجلاء الذي هده

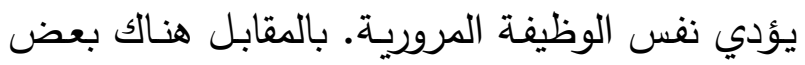

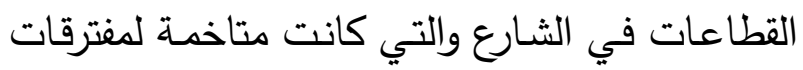
مروريــة ذات حركــة مروريــة كثيفـة، حيــث تـراوح

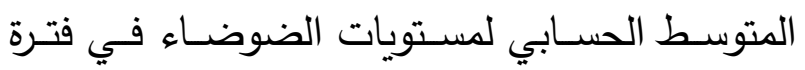

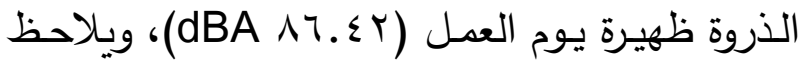

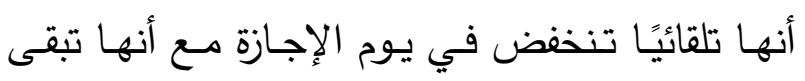
مرتفعة نوعًا ما في فترة الذروة في يوم الإجازة.
كانت بين (dBA MA.NV) حيث تركزت في منطقة مفترق الثعبية ومفترق ضبيط ومجمع الثفاء الطبي،

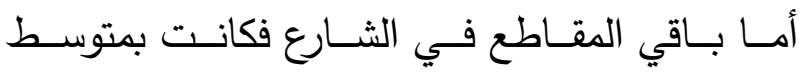
( dBA ^ ) ، ومـن الملاحظ أن المستويات في قيم التلوث الضوضائي المروري في نفس الفترة في يوم إجازة كانت في نفس المستوى متقاربـة، وذلك لك لكيك دليل على كثافة الحركة المرورية. - شـارع جمـال عبــ الناصـر هـو المـوازي مـن

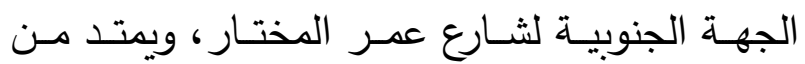

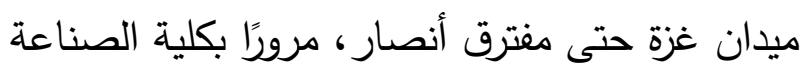

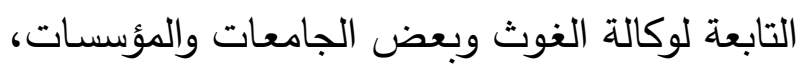

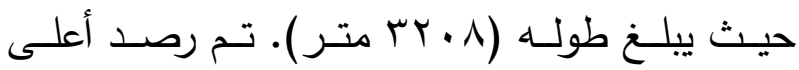

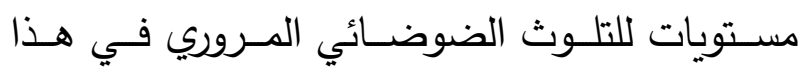

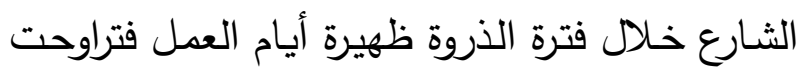

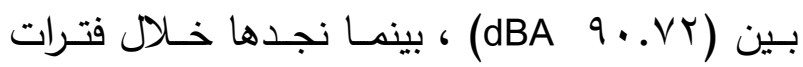
الرصد الأخرى بمتوسط (dBA A A.90) وهي فترة الصباح في أيـام العهل. كمـا لوحظ خـلال الفترتين الصباح والذروة في أيام العمل تزداد الحركة المروريـة

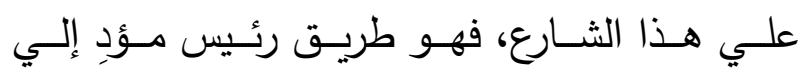

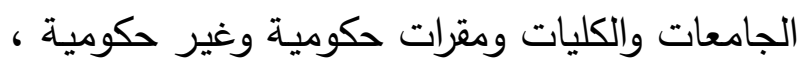
مما ينعكس علي حجم تلوث الضوضـاء المروري، بينما تتخفض بشكل حاد وملحوظ في أيام الإجازات حـول منطقـة الجامعـات، حيث أن هـا الانخفـاض لئل يتوافق في معدلاته مع معدلات الضوضـاء الصحية 
ا ـ طبيعة انتشار الضوضاء المرورية نهارا في

$$
\text { الشوارع الرئيسة في المدينة. }
$$

Y. تصنيف الطرق الرئيسـة حسب مستويات

الضوضاء المرورية فيها.

r. تصنيف منطقـة الدراسـة حسب مسـتويات

الضوضاء المرورية فيها.

ـ. تقدير حجم الضوضـاء الذي تتعرض لـه

واجهات المباني المحاذية للطرق الرئيسة.

0.تقدير حجم السكان الذين يتعرضون إلى

ضوضاء غير صحية حسب معايير منظمة الصحة

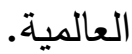

ختامًا تم عمل تحليـل إحصــئي مبسط مـن

خـلال البرنـامج ، باسـتخدام أداة الاسـتعلام المكـاني

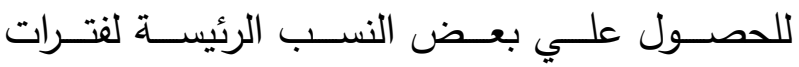

الضوضــاء المروريـة، وعلاقتهـا بكل مـن :السـكان

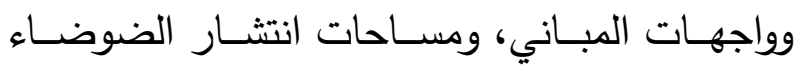
المروريـة. حيث لـوحظ أن قرابـة ، ـ ٪ مـن مسـاحة

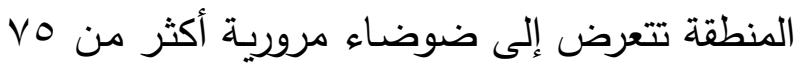

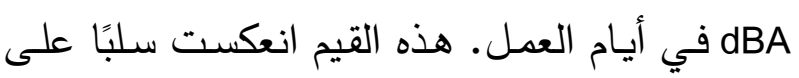

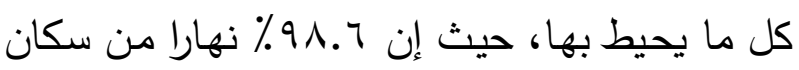

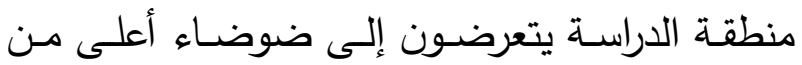

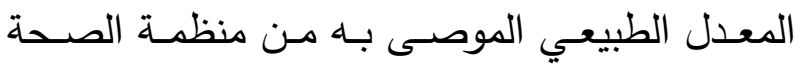
العالمية (dBA 00 نهارا).

بالنسـبة للمبـاني السـكنية فـي المنطقــة فلقـد تأثرت تدريجيا بقربها من شوارع الدراسـة، حيث إن
كما يمكن ترجيح عدة أسباب أثرت في خفض مستويات تلوث الضوضاء المروري بشكل عام خلال مقاطع هذا الشارع، ونذكر أهمها: ا ـوجـود شــارعين مــوازيين لهــذا الثــارع،

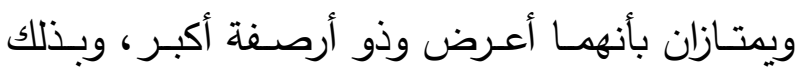
تتيح لحركة مرورية كبيرة ومريحة وهما شارع الجلاء وشارع الشفاء إضافة لأنهما بذلك خففا من الازدحام

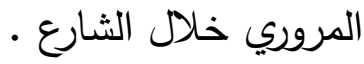

r. بسبب عرض الثارع الذي لا يماثل عرض

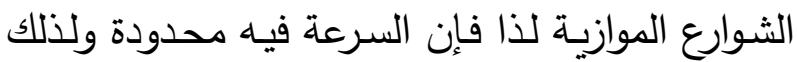
نجد معظم السائقين لا يفضلون المرور منه. r. الكثافة السكانية على جانبي الطريق تبدو

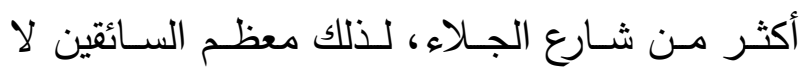
يفضلون المرور فيه.

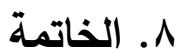

لوحظ أن النتائج الظـاهرة كانت متفاوتـة بنـاءً على النشـاطات التي تشـخل هذه الشـوارع والمرتبطـة بالعواهل البشرية بشكل خاص، حيث وصلت إلى

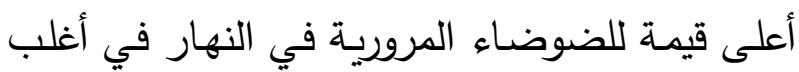
الثـوارع إلى ل 9 dBA في ظهيرة يوم عمل، وأقلـ قيمة وصلت إلى • \& dBA في صباح يوم إجازة. تم تحليل هذه القيم من خلال البرنامج ومن ثم

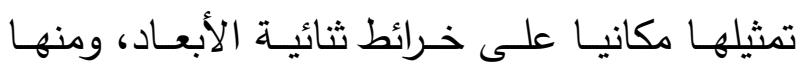
ثلاثية الأبعاد كما يلي: ت بلئي 
^- - تطبيق دراسـات للكثافة المروريـة بشكل تحليلي ودقيـق لكافـة مفترقـات المدينــة والاسـتعانة

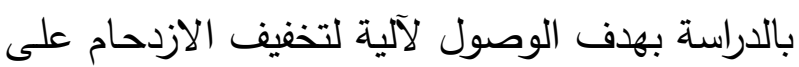

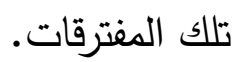

9- زيادة نشر الوعي بين السائقين بأخلاقيـة السياقة وما يجب عليه للحفاظ على الصحة العامة. والتوعيـة المجتمعيـة لخطـورة هـذه المشـكلة وكيفيـة العمل على تخفيفها والوقاية منها.

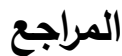

الأحســاب، إبـراهيم سـليمان، الإنسـان والبيئحة

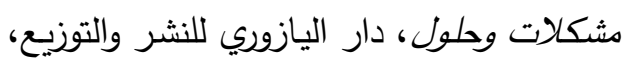

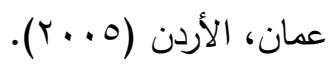
الشوكي، محمد علي مصلح، التلوث الضوضائي

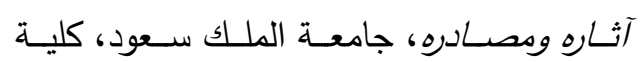

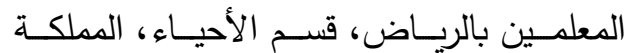

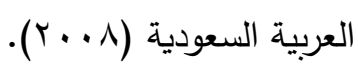
الفيفي، حسن يزيل، والهزري، عبد الله فائز، والعتيبي، تركي قاعد، التلوث الضوضائي،

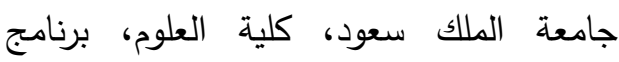
الماجستير في العلوم البيئية، المملكة العربية

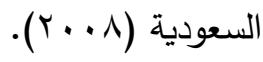
فوزي، هيثم عبدالقادر، ما هـي الضوضـاء

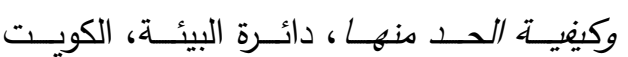
.$(r+$. الجهاز المركزي للإحصاء الفلسطيني، التعد/د

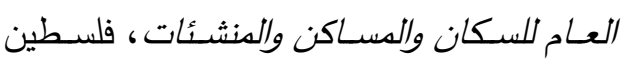
.$(r \cdot 1 \cdot)$

[०]

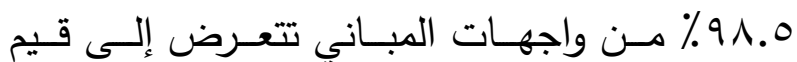
ضوضـاء أعلى من dBA 00 بشكل يومي في أيام

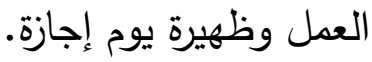

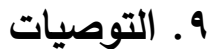

هناك بعض التوصيات المقترحة نهايـة هذه الدراسة للحد من هذه المشكلة حاليا ومستقبليا منها: 1- تطـوير هـذه الدراسـة بتقنيـات ووسـائل

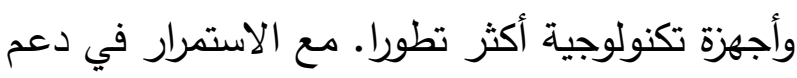
وتثجيع دراسات أخرى في هذا المجال. r- تطبيـق هذه الدراســة في أمساكن ومنـاطق أخرى لتشمل عددًا كبيرًا من الشوارع والطرق الرئيسة. ب- تتظيم الحركـة المروريـة على المفترقـات الأكثر ازدحاما خصوصًا في أوقات الذروة. ع- إعادة النظر في التخطيط لبعض الطرق

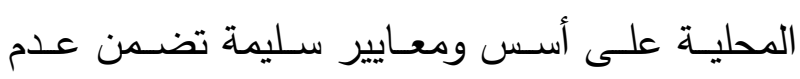

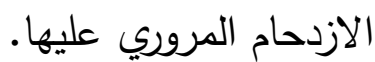

0- تعــويض الــنقص فــي أدوات الــتحكم والإثــارات المروريــة ومواقـف السـيارات مـن قبـل

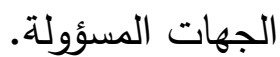

צ- سـن وتطبيـق الأحكـام واللـوائح القانونيـة لتنظيم هذه المشكلة. V- زيادة التشجير على جوانب الطرق لما لها من دورِ كبيرِ في امتصاص جزء كبير من مستويات

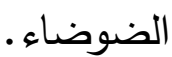


International Master's Program in Geo informatics, Sweden (2008).

الجزار، محمد، تقييم ومحاكاة نظام المواصلات

في مدينة غزة باستخدام برامج نظم المعلومات

الجغرافيـة والترانسـكاد، ســالة ماجستير ، كليـة

الهندسـة، الجامعـة الإســلامية بغـزة، فلسـطين

$\cdot(r, I Y)$

السراج، يحيى رشدي، دليل إحصائي لحركة

المرور في قطاع غزة، جمعية نطوف للبيئة

$$
\text { وتتمية المجتمع (0. . ب). }
$$

$$
\begin{aligned}
& \text { الـــدويكات، قاســــم محمد، أنظدــة المعلومــات } \\
& \text { الجغرافية، عمان: المكتبة الوطنية ( . . ؟ ). } \\
& \text { زرقطـــه، هيــثم يوســف، نظـــم المعلومــات } \\
& \text { الجغرافيـة: الـدليل العملـي، دار الثـعاع للنشـر } \\
& \text { والعلوم، دمشق (Y. . . . . ). }
\end{aligned}
$$

Kleaboe, R., Nordic Perspective on Noise Reduction at the Source. TOI report 806 (2005).

EPA, Noise measurement procedure manual, Environmental Protection Agency, Second Edition, July 2008. Tasmania, Australia. ISBN-13:978-0-9805182-1-4 (2008).

Farcas, F., Road Traffic Noise: A study of Skane region, Sweden. Linkoping University, 


\title{
Using GIS in Evaluation of the Traffic Noise Levels in Gaza City-Palestine
} Alaeddinne Eljamassi ${ }^{1}$ and Ghassan Al Borsh ${ }^{2}$

\author{
${ }^{1}$ Civil Engineering Department, Faculty of Engineering, and ${ }^{2}$ Faculty of Science, IUGaza, Palestine
}

Abstract. Environmental pollution is one of the most important problems that threaten our world because of its direct relationship with human activity. One of the most important pollutants is the noise pollution. Noise pollution in Gaza strip in Palestine is progressively growing and increasing due to many factors, which include natural factors, artificial factors, technological factors and others. It was noticed that the traffic noise is one of these major factors. The aims of this study are: 1) Using the Geographic Information System (GIS) technique in making a precise analytic study of the behavior of spread of traffic noise phenomenon. 2) Numerically modeling in order to appreciate its effects on the population and the surrounding environment via one of the most important of GIS Software (ArcGIS9.3). The practical research methodology depended on getting the true values of noise in dBA, using auto range Digital Multi Meter after determining the areas geographically, using the GPS during two peaks (morning, afternoon) in work days as well as in holidays. After the analysis process in the program and counting the noise LeqA, the results in the city reflected a dangerous effect of this phenomenon as the highest value of traffic noise LeqA in the morning of most roads reached $91 \mathrm{dBA}$ in the afternoon workday, while the lowest value reached $40 \mathrm{dBA}$ in the holiday morning. The classification was performed for the five main roads and the study area, depending on its exposure to noise, and it was found that about $40 \%$ of the area is exposed to traffic noise more than $75 \mathrm{dBA}$ and $9 \%$ of the area is exposed to the same degree of traffic noise in holidays. Also, it is noticed that these values were reflected negatively in the surrounding as $98.6 \%$ of the population in the morning are exposed to noise that is higher than the normal average ( $55 \mathrm{dBA}$ in the morning). Regarding the residential buildings in the area, they were affected gradually because of being close to the study roads as $98.5 \%$ of buildings facades are exposed to noise values higher than $55 \mathrm{dBA}$ daily in workdays and in holiday's afternoon. Finally, all the previous results were presented as digital maps to facilitate reading and to well appreciate by the decision makers, in order to find environmentally effective solutions.

Keyword: GIS, Modeling of noise pollution, Traffic noise, Gaza city, Palestine. 